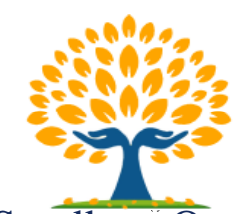

SvedbergOpen DISSEMINATIONOFKNOWLEDGE

\section{International Journal of A rtificial Intelligence and M achine Learning}

Publisher's HomePage: https:/ / www.svedbergopen.com/

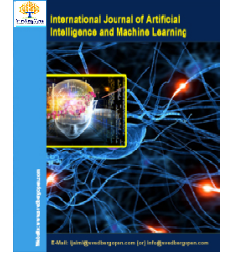

Open A ccess

\title{
Machine Learning-Algorithmic Trading Strategies for Superior Growth, Outperformance and Competitive Advantage
}

Nicholas Burgess ${ }^{1 *}$

${ }^{1}$ Saïd Business School, University of Oxford, UK. E-mail: nicholas.burgess@sbs.ox.ac.uk

\section{Article Info}

Volume 2, Issue 1, January 2022

Received : 06 April 2021

Accepted : 19 November 2021

Published : 18 January 2022

doi: 10.51483/IJAIML.2.1.2022.38-60

\begin{abstract}
"Did algorithmic trading generate superior returns relative to discretionary trading during the Covid19 pandemic and do they provide a sustainable competitive advantage?" In this paper we use the tools and frameworks from Oxford University's postgraduate diploma in financial strategy to answer this question and study the performance and benefits of algorithmic trading strategies (algos), and specifically those that use Artificial Intelligence (AI) and Machine Learning (ML). We discover using valuation theory from (SBS2, 2020) that algos generate superior returns compared to human discretionary trading both in normal market conditions and during large market drawdowns, such as during the coronavirus (Covid-19) pandemic. Furthermore applying financial strategy techniques from (SBS1, 2020) we found that algos could be combined with existing core competencies at my organization RUS to create a sustainable competitive advantage and give RUS an edge over its competitors. Finally, considering M\&A growth strategies from (SBS4, 2020) we conclude that for RUS algorithmic trading capabilities would be best acquired taking an organic approach as an in-house build approach would be both cost-effective and allow for a more customized and bespoke integration. Even if only a fraction of the potential benefits are monetized, algo trading could have a significant positive impact on earnings, which in turn would allow for reinvestment to facilitate sustainable growth and maintain a sustainable competitive advantage.
\end{abstract}

Keywords: Algorithmic trading, AI, machine learning, Covid-19, PESTEL analysis, SWOT analysis, VRINO analysis, strategy canvas

() 2022 Nicholas Burgess. This is an open access article under the CC BY license (https: //creativecommons.org/licenses/by/4.0/), which permits unrestricted use, distribution, and reproduction in any medium, provided you give appropriate credit to the original author(s) and the source, provide a link to the Creative Commons license, and indicate if changes were made.

\section{Introduction}

The current Covid-19 pandemic required that the financial services industry invest heavily in technology and cyber security in order to facilitate remote working, whilst adhering to strict regulation controls to keep businesses and data secure. Opportunistic and prudent investment firms could leverage such technology investments to invest in high growth opportunities and increase their algorithmic trading capabilities.

In times of crisis trading systems using artificial intelligence and machine learning have the potential to provide a competitive advantage as they constantly adapt to market conditions (JP Morgan, 2019). They have the ability to process vast amounts of traditional, social media and alternative reference data at high speed to gauge market sentiment.

\footnotetext{
* Corresponding author: Nicholas Burgess, Saïd Business School, University of Oxford, UK.

E-mail: nicholas.burgess@sbs.ox.ac.uk
} 
Moreover, they can manage more highly diversified portfolios to reduce idiosyncratic risk and increase Sharpe ratios ${ }^{2}$ (Esposito, 2020; and Institutional Investor, 2020).

In this paper we study if algorithmic trading strategies generate superior returns, if they could provide a sustainable competitive advantage relative to discretionary (or human) trading and we consider how to best acquire and integrate algo capabilities at RUS.

We proceed as follows: Firstly, we give an overview of the current market environment. Secondly, we introduce algorithmic trading and outline the main machine learning techniques and how they can be used. Thirdly, we compare the performance of algos and discretionary trading systems using a hedge fund case study, where we classify funds by their investment strategy. Fourthly, we investigate if algos could provide a sustainable competitive advantage and fifthly, we consider how organization RUS should acquire and integrate algo capabilities with existing skills and resources.

\section{Current Environment}

The ongoing coronavirus (Covid-19) global pandemic (2019-2021) has caused widespread distress, disruption and as of January 2021 has claimed the lives of more than 2.2 million people (WHO, 2021). The attempts of Governments to control the virus through lockdowns and curfews have harmed economies and businesses, particularly those in the hospitality, travel and tourism sectors. Digital organizations, technology stocks and the FANGs ${ }^{3}$ have strongly outperformed (Wigglesworth, 2020), whereas many businesses unable to adapt to online working have suffered losses, faced closure and bankruptcy (Skeel, 2020).

Despite the development of new vaccines to counter the pandemic, many are still wondering what a recovery could look like and businesses need to consider the possibility of tail risks such as coronavirus mutation and further pandemics.

The new normal way of life relies on technology, with day-to-day business being conducted online using technologies, such as, Skype, Microsoft Teams and Zoom. Consequently to survive many businesses had no choice but to invest in technology and infrastructure to facilitate the high demand for online working and manage the associated cyber security risks.

To more formally assess the current macro environment and highlight opportunities and threats relevant to the financial services industry we perform a PESTEL analysis (Whittington et al., 2020). The analysis is categorized into six environmental factors, namely Political, Economic, Social, Technological, Ecological and Legal and is often used to aid macro forecasts and scenario analyses.

In Figure 1 we build upon and extend the PESTEL analysis from Burgess (2020b) to incorporate the most recent Covid-19 impact assessments on the broad macro environment see (McKinsey, n.d.; and McKinsey, 2021).

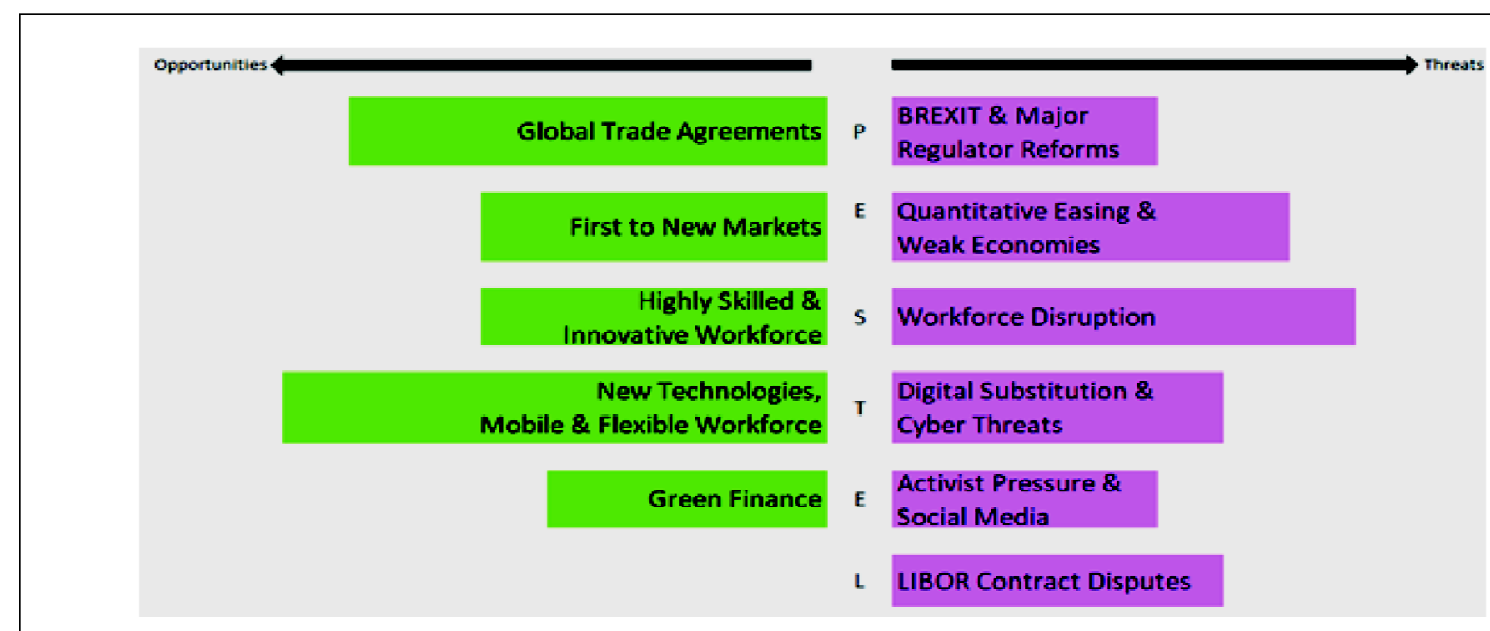

Figure 1: PESTEL Analysis for Financial Services

Source: Macro Scenario Analysis of Financial Services (Burgess, 2020b)

See Appendix for full case study details.

Sharpe ratios measure performance as the return of an investment per unit risk.

The FANGs are the four prominent tech stocks in the US, namely, Facebook, Amazon, Netflix and Alphabet (previously Google). The equivalents in China are the BAT stocks Baidu, Alibaba and Tencent. 
Key highlights stem from the broad economic impact of the Covid-19 pandemic, which has required quantitative easing and government stimuli to counter the effect of mandatory lockdowns, workforce disruption and business closures. In the US alone, the economy is estimated to incur net GDP losses ranging from $\$ 3.2$ tn (14.8\%) to $\$ 4.8$ tn (23.0\%) over a 2-year period. (Walmsley et al., 2020).

Furthermore investment in new technologies facilitates a mobile, flexible workforce and enables remote working to keep businesses open, but also presents opportunities to exploit competitor weakness and capture market share due to the different levels of business readiness and technological capacity in the industry. Prudent and opportunistic investment firms could invest in technologies with a high growth potential, such as, algorithmic trading, to gain a sustainable competitive advantage.

\section{What is Algorithmic Trading?}

As outlined in Burgess (2019a), algorithmic trading (or systematic trading) refers to the automation of the trading process, through the creation of predefined rules (the 'trading system') and their strict application when executing financial market transactions. The automated trading system benefits from being repeatable and testable, unlike discretionary trading (or human trading), which potentially has different rules for every transaction.

Algorithmic trading systems are predominantly employed by Hedge Funds to create leveraged alternative investment portfolios uncorrelated with the market. Currently the world's hedge funds have USD3.1 tn assets under management (Statista1, n.d.). The largest hedge funds by assets under management (AUM) are illustrated in (Figure 2). Similarly algos are used by High Frequency Trading firms (HFTs) to make markets, seek liquidity rebates and exploit market inefficiencies to benefit from arbitrage opportunities (Brogaard et al., 2011).

in June 2020 (in USD billion)

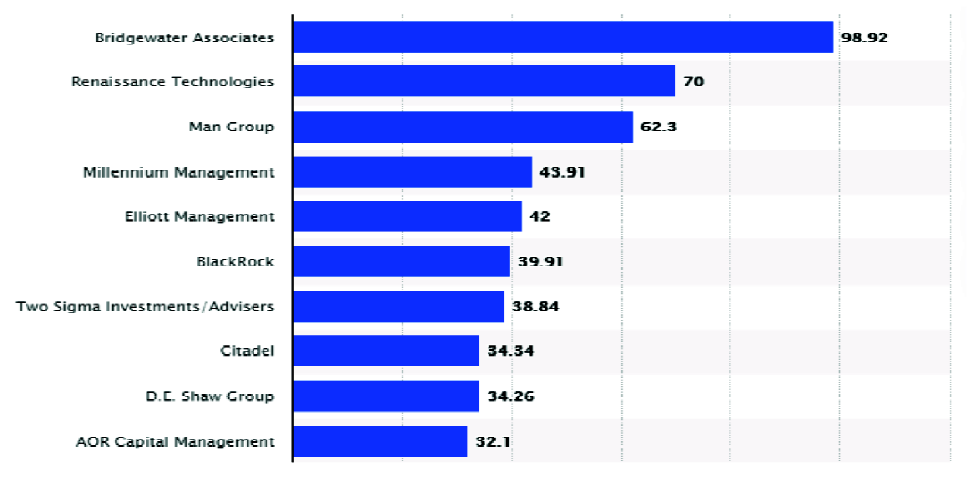

Figure 2: Assets Under Management (AUM) of the Largest Hedge Fund Firms Worldwide in June 2020 (in USD bn)

Source: Statista2 (n.d.)

A recent survey by Barclay (2018) asked managers of hedge funds and Commodity Trading Adviser funds (CTAs) for their insights and experience with $\mathrm{AI}$ and machine learning and found that:

- $\quad$ More than half managers use AI/ML to inform investment decisions.

- $\quad$ Two-thirds of funds use AI/ML to generate trading ideas and optimize portfolios.

- $\quad$ Over a quarter use automation to execute trades.

- Well over half have used AI for three or more years, and a third of hedge funds have used AI over five years.

Market drawdowns provide an excellent stress test of an algorithmic trading strategy's usefulness and ability to outperform. In 2020 financial markets were in turmoil and suffered heavy losses due to the devastating impact of the coronavirus global pandemic. In the US, as shown in Figure 3, markets plunged 38\% in March 2020 to recover in April 2020 and the subsequent months. This pattern was observed in many markets and exchanges globally. 


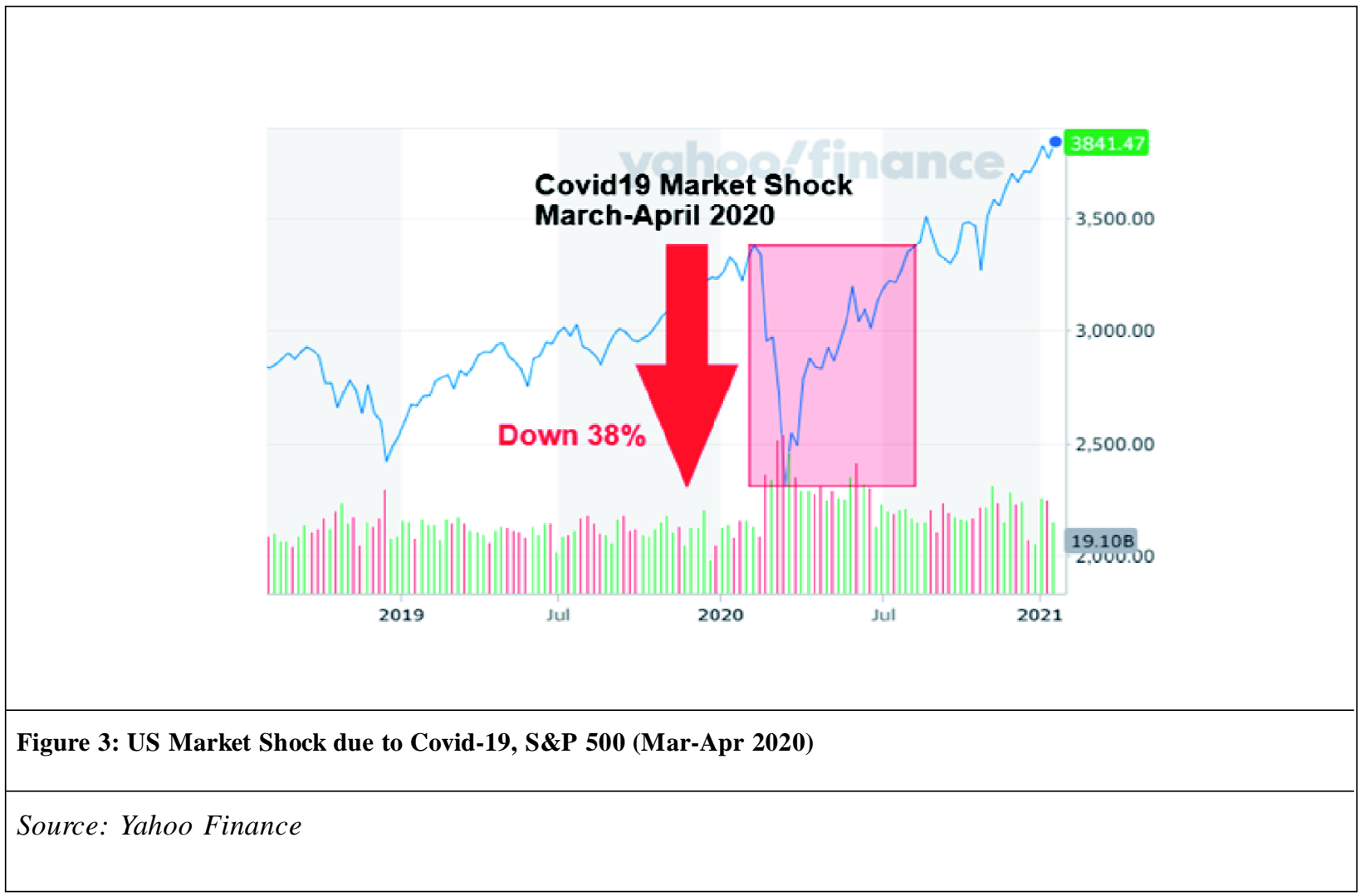

During the Covid-19 pandemic hedge funds using algorithmic trading strategies suffered heavy losses. Many trading strategies were trained to follow predefined trading signals that were not able to adapt the new market environment. Consequently human-run hedge funds trounced Quant funds (Bloomberg, 2020). For example, as shown in Figure 4, in equity markets discretionary funds beat systemic funds during the Covid19 market shock and performed much better than Quants models and systematic investing (Factor Research, 2020).

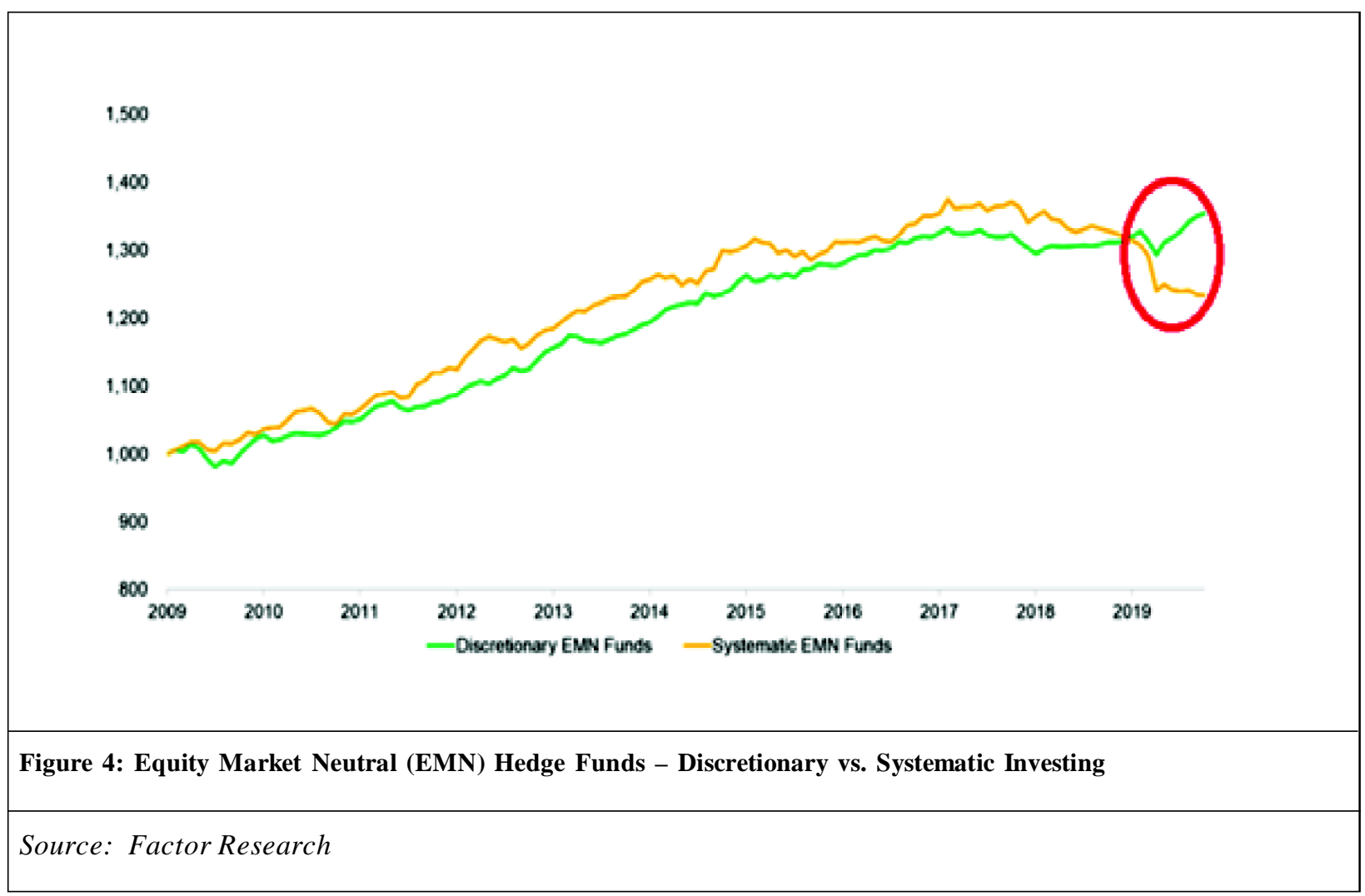


However artificial intelligence funds vastly outperformed discretionary funds with their trading strategies having the ability to continually process, learn and adapt to new market conditions. Reports such as Institutional Investor (2020) and Robinson (2020) claimed that AI funds generated returns almost three-times higher than that of other hedge funds. Both, Friedman (2019) and Eurekahedge (2018) also confirm that AI and machine learning funds generated superior returns as shown in Figures 5 and 6 below.

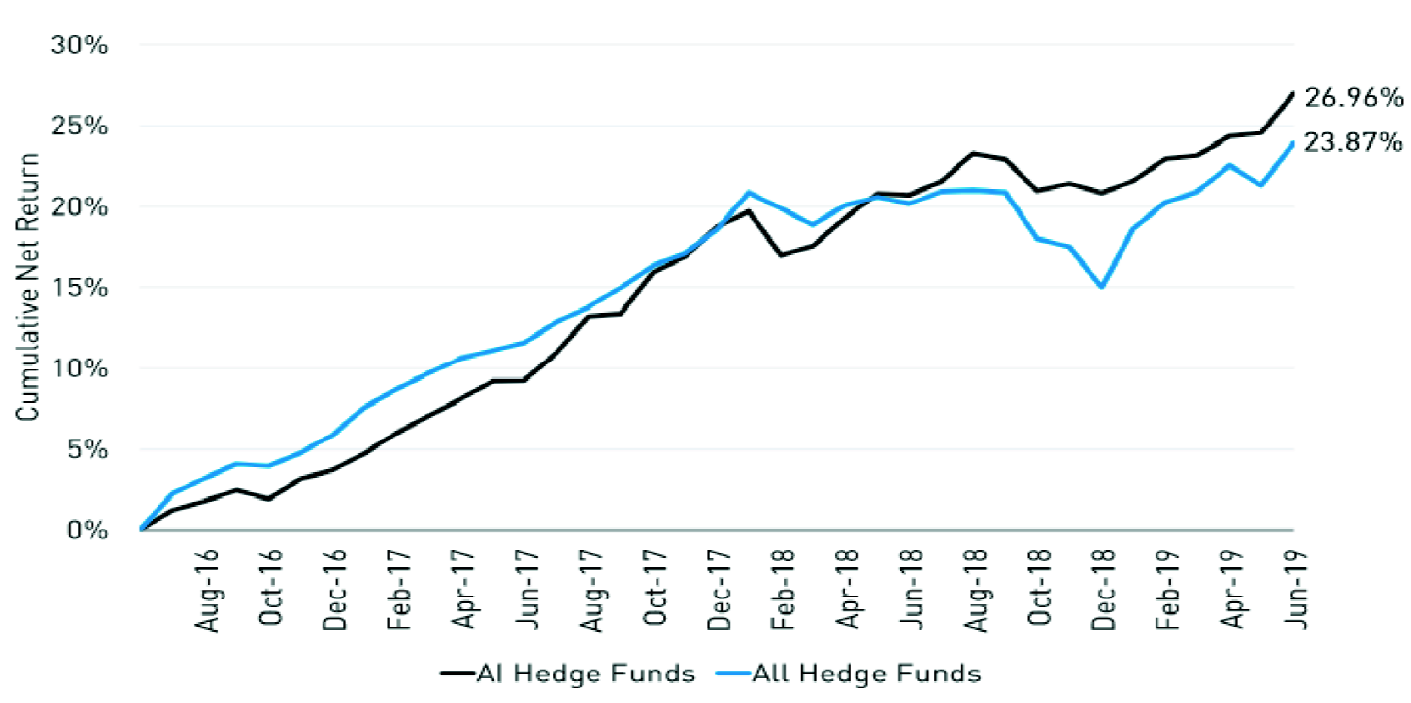

Figure 5: Cumulative 3-Year Returns: AI Hedge Funds vs. All Hedge Funds

Source: Prequin Blog (Friedman, 2019)

Prequin performance benchmarks show that AI fund returns have outperformed the all hedge fund benchmark by $3.09 \%$ with lower volatility and higher Sharpe ratios. AI funds reported 3.20\% volatility and a Sharpe ratio of 1.96 , while the hedge fund benchmark posted volatility of $3.87 \%$ and a Sharpe ratio of 1.40 .

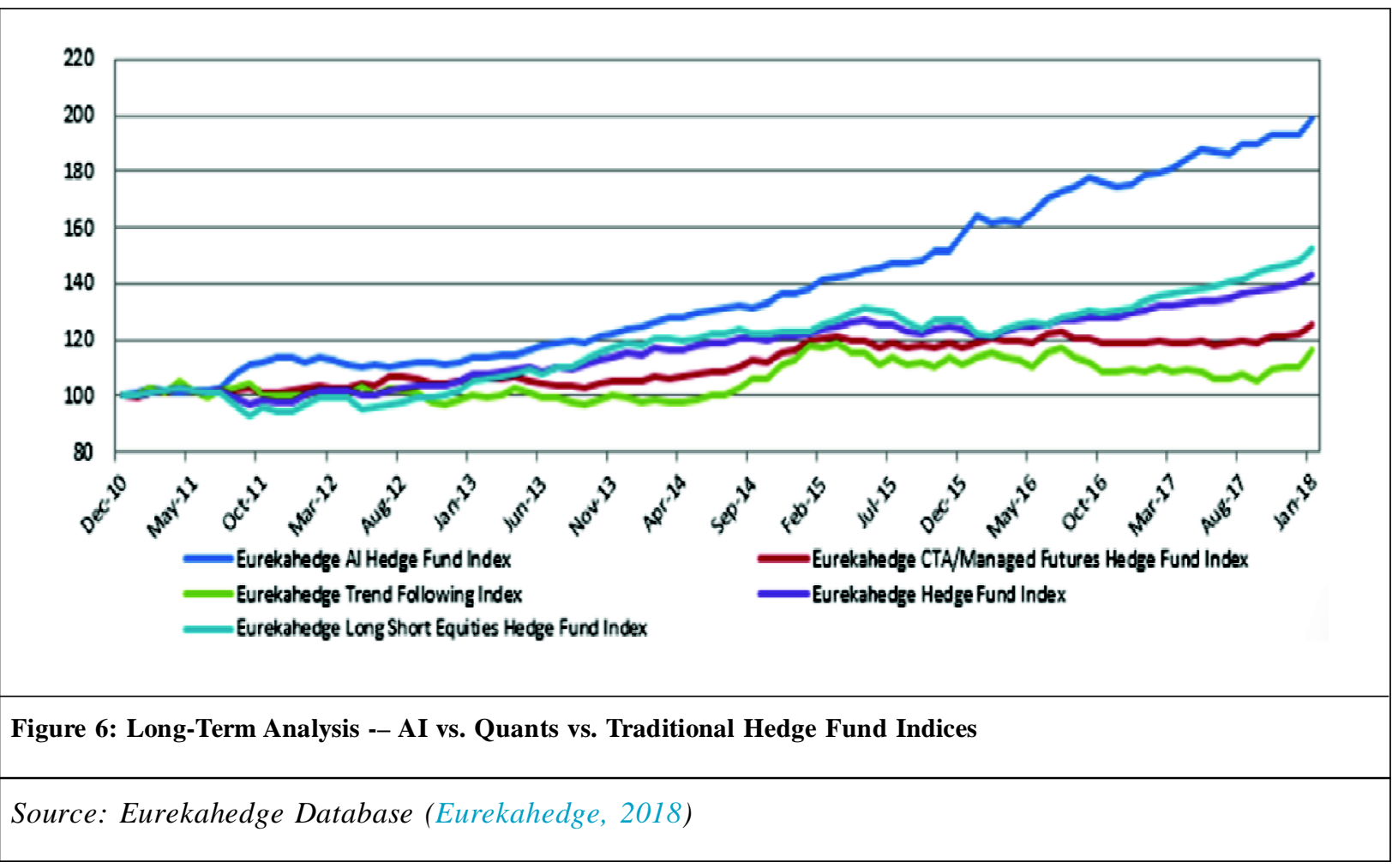


Consequently, from here onwards we focus on algorithmic trading systems that use artificial intelligence, machine learning and predictive technologies to make investment decisions as we look to answer the headline question and investigate if algorithmic trading generated superior returns relative to discretionary trading during the Covid-19 pandemic and if they could provide a sustainable competitive advantage.

Machine learning funds try to incorporate and adapt to live market data and current sentiment as much as possible. They go far beyond traditional back-testing approaches and the use of fundamental and technical analysis to generate alpha. They look for patterns in current market micro-structure ${ }^{4}$ and gauge current market sentiment, using behavioral science, neuro-linguistic programming, Natural Language Processing (NLP) and deep data techniques to interpret and process enormous volumes of text, speech and sentiment from social media, news channels and alternative reference data in real time, see Lüpez de Prado (2018) and Wyman (2014).

The processing of vast amounts of data in real time is an impossible task for human traders. Consequently discretionary traders are forced to concentrate their efforts on a handful of securities compared to the machine learning funds that are able to diversify far more broadly. Algorithmic trading strategies characteristically hold a large number of securities to take advantage of the law of large numbers and statistical edges. This diversification reduces idiosyncratic risk, a risk that the Capital Asset Pricing Model (CAPM) says can be diversified away and consequently investors are not rewarded for, see Berk and DeMarzo (2016), Brealey et al. (2014) and Burgess (2021). As a result machine learning portfolios have the potential to be more efficient in the CAPM sense and to intrinsically carry lower risk, which increases Sharpe ratios.

Machine learning techniques are broadly categorized as being supervised or unsupervised. Supervised techniques are given pre-classified data to train the model, whereas unsupervised learning techniques must discover trends, features, relationships and classify data on their own. We outline several of the main machine learning classification techniques below (Wilmott, 2019) for more information and examples of usage.

\section{1. $K^{\text {th }}$ Nearest Neighbors $(K N N)$ - Supervised Learning}

We start out with $\mathrm{N}$ data points that are already classified into groups or features. New data is classified as being in the most popular group as determined by the $\mathrm{K}^{\text {th }}$ nearest data points. For example, given a list of trading features that constitute a buy, sell or hold signal, what does the current market features suggest we should do?

\subsection{K Means Clustering (KMC) - Unsupervised Learning}

Given unclassified data points represented by feature vectors ${ }^{5}$ we gather them into $\mathrm{K}$ groups associated with their centers of mass or centroids. This is useful for measuring financial data that clusters or is mean reverting, such as interest rate or volatility levels.

\subsection{Nä̈ve Bayes Classification (NBC) - Supervised Learning}

Given samples of data representing different classes we calculate the probability of new data being in each class. This technique is useful for Natural Language Processing (NLP) and analyzing social media and news data for sentiment.

It uses Bayes Theorem, where $\mathrm{P}(\mathrm{A} \mid \mathrm{B})=\mathrm{P}(\mathrm{B} \mid \mathrm{A}) \cdot \mathrm{P}(\mathrm{A}) / \mathrm{P}(\mathrm{B})$ to determine, for example, the probability a news article with the words "Positive" and "Earnings" is a good news article that will move stock prices upwards,

$P($ Good News $\mid$ Uses the words Positive , Earnings $)=$

$\frac{P(\text { Uses the words Positive, Earnings } \mid \text { Good News }) . P(\text { Good News })}{P(\text { Uses the words Positive, Earnings })}$

\subsection{Support Vector Machines (SVM) - Supervised Learning}

Given a set of classified data represented by vectors of features, we divide the data using a hyperplane and classify new data according to which side of the hyperplane each data point lies. This is useful for detecting when trading levels are rich or cheap.

\footnotetext{
4 A simple example being the cancellation of many sell orders might indicate an imminent uptick or rally.

5 Each data point is represented as a list of features describing the data, commonly referred to as a feature vector.
} 


\subsection{Self-Organizing Maps (SOM) - Unsupervised Learning}

We start with all our data points represented as feature vectors. We then map similar data and features into a twodimensional grid to visualize which data have similar characteristics. This is useful for hedging and identifying stocks for pairs trading. It is also useful in Modern Portfolio Theory (MPT) whereby stocks can be grouped into buy and sell categories based on expected returns, volatility and correlations between stocks.

\subsection{Decision Trees - Supervised Learning}

This is a flowchart technique and uses a hierarchy of features to divide (split) and classify data. They are often referred to as Classification and Regression Trees (CART). This could be used to analyze winning and losing trades for example (Figure 7).

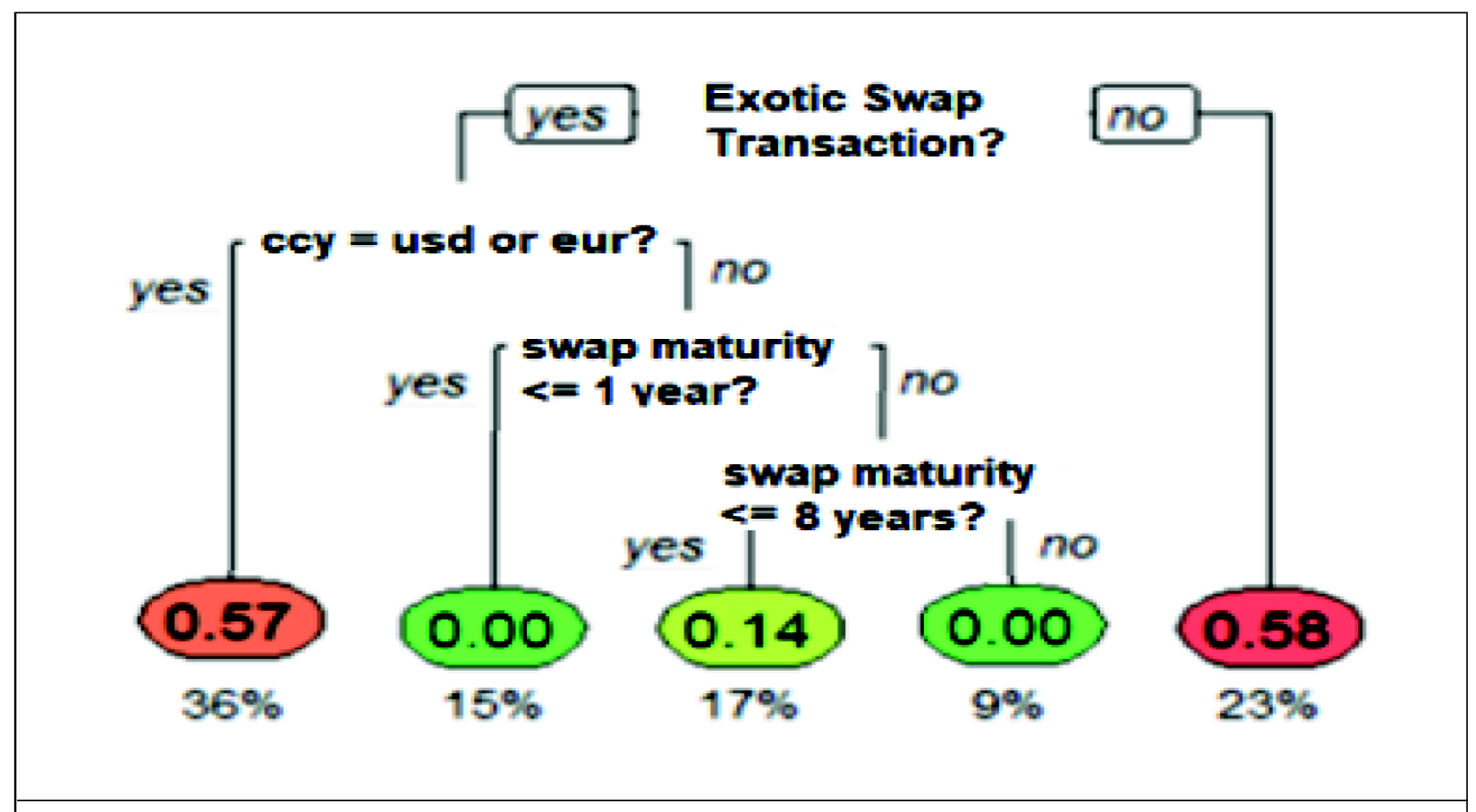

Figure 7: Decision Tree Example for Interest Rate Swap Transactions

Source: Adapted from Wikipedia

The example tree estimates the probability of an interest rate swap transaction being profitable (winning) given the transaction type exotic or vanilla, the currency of the swap and the maturity, where the decimal inside the node represents the probability and the percentage of transactions in the category is outside the node.

\subsection{Neural Networks - Supervised and Unsupervised Learning}

A type of machine learning that tries to mimic brain activity. Signals are passed through a network of neurons where they are mathematically manipulated and passed on for further processing. They are used for modeling complex financial relationships, establishing the functional form of data and pattern recognition.

\subsection{Reinforcement Learning - Unsupervised Learning}

This is one of the main types of machine learning, where the algorithm uses trial and error and is based on system of rewards and penalties. The algorithm uses a heuristic function to track the score of each trial run and is trained to maximize the score. This method is useful for learning how to trade optimally in highly volatile markets and interact with in environment when there is high uncertainty.

Trading strategies using supervised techniques often use historical data for pre-classification, however past performance is no guarantee of future results. Unsupervised learning approaches rely less on historical trends and seek to constantly learn and adapt to new market environments. Consequently they require large representative data sets to be effective, eliminate bias and error (Lynch, 2018). Unsupervised strategies are perhaps well placed to manage market shocks such as those faced during the Covid-19 pandemic. However, it is a balancing act as fund managers do not want 
trading systems to react too quickly to noise in the market information nor so slowly that they miss a trend. Perhaps this suggests that some human oversight may be helpful.

In summary algorithmic or systemic trading is simply the automation of the trading process, which could involve full or partial automation of the trading system including trading signal classification, trade execution, hedging and the risk management process. In theory such trading systems are ideal to monitor, adapt and respond to new market conditions not seen before, such as those experienced during the Covid-19 pandemic, but how did they perform in practice?

\section{Algorithmic Trading Performance}

In this section we study at algorithmic trading performance during normal market conditions and market shocks such as that during the Covid-19 pandemic (Figure 3). We perform a case study analysis comparing artificial intelligence tech fund performance with that of quant and discretionary funds. We ask the reader to note that when evaluating and comparing fund performance there are many factors to consider including investment manager skill and ability, fund size, market sectors invested in, FX and currency market fluctuations, market inflation factors etc. Relative performance does not reflect on causality and cannot be fully attributed to the skill of the investment manager. Relative performance is purely suggestive and used to highlight the potential for algorithmic trading and predictive technologies to provide a competitive advantage.

\subsection{Measuring Hedge Fund Performance}

When comparing hedge fund performance it is not sufficient to only consider fund returns, as investors can increase returns by leveraging positions and taking more risk. Consequently fund performance is measured using risk-adjusted returns, i.e., return per unit risk, which gives a convenient uniform performance measure that can be applied to all funds. No trading strategy or fund can be profitable at all times and during all market conditions, consequently investors pay close attention to fund drawdowns, both the size and frequency of losses suffered by the fund.

There are several measures of fund performance (Steinki and Mohammad, 2015), each with different pros and cons. The main measure used is the Sharpe Ratio defined in Equation 1. Other measures include the Sortino Ratio that only measures downside risk (negative variations) and the Treynor Ratio which measures risk as CAPM Beta (Burgess, 2021).

\section{Equation 1: Sharpe Ratio(SR)}

$$
\text { Sharpe Ratio }=\left(\frac{r_{p}-r_{F}}{\sigma_{p}}\right)
$$

where $r_{P}$ denotes the return of a portfolio, $r_{F}$ is the risk-free rate, and $\sigma_{P}$ is the annualized volatility or standard deviation of portfolio returns with all units in $\%$.

\section{Example 1: Sharpe Ratio}

Consider two investment funds A and B having an average annual return $12 \%$ with incremental drawdowns of 5\% and $10 \%$ respectively. Clearly fund A performs best as it bears less risk for the same return. If it is known the risk free rate is $2 \%$ for our investment horizon then using (Equation 1) we have Sharpe Ratio (fund A) $=(12 \%-2 \%) / 5 \%=2.0$ and Sharpe Ratio $($ fund $\mathrm{B})=(12 \%-2 \%) / 10 \%=1.0$.

A fund's performance is not only due to its ability to generate superior returns, but also its ability to minimize risk and limit the size and frequency of its drawdowns. Consequently, we review fund performance not just in normal market conditions but also during the Covid-19 market shock, as illustrated in Figure 3, when many funds were experiencing large drawdowns. We investigate which funds generated superior returns on a risk-adjusted basis and also examine which funds suffered fewer and smaller drawdowns during the Covid-19 pandemic.

\subsection{Hedge Fund Performance}

To assess relative hedge fund performance we used Eurekahedge data. Eurekahedge is one of the world's largest hedge fund and private equity databases. For our analysis we used the hedge fund indices and benchmarks outlined in Table 1. These hedge fund indices represent collections of hedge funds by fund type.

These indices represent broad groups of hedge funds by fund type. The exact fund definitions are available from (Eurekahedge, n.d.) or via the Bloomberg terminal.

We extended a previous study (Eurekahedge, 2017) using (Eurekahedge, n.d.) to collect and collate more recent fund performance data covering the Covid-19 period. We present a summary of results above in Table 2. 


\begin{tabular}{|c|c|c|}
\hline Hedge Fund Index & Bloomberg Ticker & Fund Type \\
\hline Al Hedge Fund Index & EHFl817 Index & Artificial Intelligence Hedge Funds \\
\hline CTA / Managed Futures & EHFI286 Index & Quant Funds - General \\
\hline Trending Following Index & EHFl808 Index & Quant Funds - Systematic Trend Following \\
\hline Hedge Fund Index & EHFI251 Index & Traditional Hedge Funds (Discretionary) \\
\hline
\end{tabular}

Source: Eurekahedge (n.d.)

\begin{tabular}{|c|c|c|c|c|}
\hline Eureka Hedge Fund Index & $\begin{array}{l}\text { Al Hedge Fund } \\
\text { Index }\end{array}$ & $\begin{array}{c}\text { CTA / Managed } \\
\text { Futures }\end{array}$ & $\begin{array}{c}\text { Trend Following } \\
\text { Index }\end{array}$ & $\begin{array}{l}\text { Hedge Fund } \\
\text { Index }\end{array}$ \\
\hline $\begin{array}{l}\text { Bloomberg Ticker } \\
\text { Fund Type }\end{array}$ & $\begin{array}{c}\text { EHFI817 Index } \\
\text { Artificial } \\
\text { Intelligence }\end{array}$ & $\begin{array}{l}\text { EHFI286 Index } \\
\text { Quant - General }\end{array}$ & $\begin{array}{l}\text { EHFI808 Index } \\
\text { Quant - } \\
\text { Systematic Trend }\end{array}$ & $\begin{array}{c}\text { EHFI251 Index } \\
\text { Traditional / } \\
\text { Discretionary }\end{array}$ \\
\hline $\begin{array}{l}\text { Statistics (as at Jan 2021) } \\
\text { Covid19 Return, Mar-Apr } 2020 \\
\text { Annualized Return } \\
2020 \text { Return } \\
\text { Return Since Inception } \\
\text { Best Monthly Return } \\
\text { Worst Monthly Return }\end{array}$ & $\begin{array}{c}3.27 \% \\
12.23 \% \\
11.24 \% \\
259.27 \% \\
8.01 \% \\
-2.88 \%\end{array}$ & $\begin{array}{c}1.82 \% \\
8.47 \% \\
7.85 \% \\
454.94 \% \\
8.33 \% \\
-4.32 \%\end{array}$ & $\begin{array}{c}4.10 \% \\
9.13 \% \\
10.92 \% \\
531.27 \% \\
9.21 \% \\
-6.70 \%\end{array}$ & $\begin{array}{c}-2.23 \% \\
8.50 \% \\
12.26 \% \\
457.99 \% \\
5.30 \% \\
-6.32 \%\end{array}$ \\
\hline $\begin{array}{l}\text { Risk / Return } \\
\text { Annualized Standard Deviaton } \\
\text { Downside Deviation } \\
\text { Upside Deviation } \\
\text { Maximum Drawdown } \\
\text { Sharpe Ratio } \\
\text { Sortino Ratio } \\
\text { Percentage of Positive Months }\end{array}$ & $\begin{array}{c}5.94 \% \\
2.25 \% \\
6.16 \% \\
-7.24 \% \\
1.72 \\
4.55 \\
73.68 \%\end{array}$ & $\begin{array}{c}6.39 \% \\
3.09 \% \\
5.88 \% \\
-6.30 \% \\
1.01 \\
2.09 \\
60.87 \%\end{array}$ & $\begin{array}{c}9.39 \% \\
5.11 \% \\
8.13 \% \\
-14.42 \% \\
0.76 \\
1.40 \\
56.92 \%\end{array}$ & $\begin{array}{c}5.07 \% \\
2.90 \% \\
4.53 \% \\
-12.27 \% \\
1.28 \\
2.24 \\
71.15 \%\end{array}$ \\
\hline
\end{tabular}

Source: Eurekahedge (n.d.)

\subsection{Algorithmic Trading Performance During Covid-19 Drawdown (March-April 2020)}

Hedge fund performance during market drawdowns is very important. It highlights the skill of the fund manager to avoid large losses and manage downside risk. Summarizing the results presented in Table 2, we see that during the Covid-19 market drawdown in March-April 2020. AI funds performed well and made gains of $+3.27 \%$ whereas traditional discretionary funds reported losses of $-2.23 \%$ over the same period.

AI funds had the lowest downside volatility of $2.25 \%$ and amongst all the hedge fund groups had one of the smallest maximum drawdowns, which for AI funds was $-7.24 \%$ compared to $-6.30 \%$ and $-14.42 \%$ for quant funds and $-12.27 \%$ for discretionary funds. 


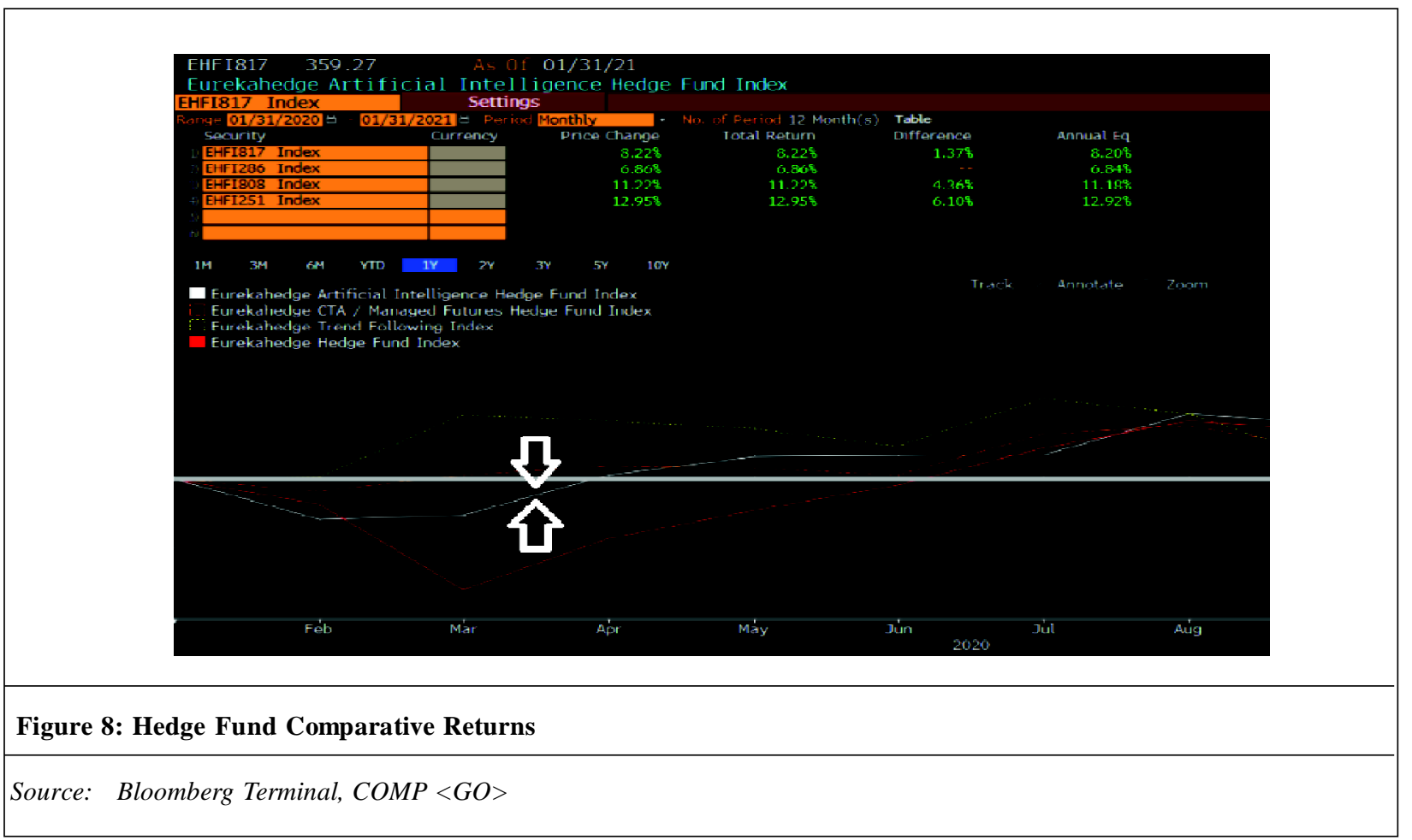

Morningstar Direct data reported that during the Covid-19 pandemic AI technology funds held up relatively well, reporting that in April 2020 as the FTSE 100 and S\&P 500 plunged more than-20\% and tech funds were down as little as $-4.6 \%$ (Esposito, 2020). Bloomberg also showed that the downside volatility of AI funds during the Covid-19 major market downturn was exceptionally small (Figure 8).

During Covid-19 market downturn and rebound in March-April 2020 the Eurekahedge Artificial Intelligence Hedge Fund Index did not suffer large drawdowns and showed little volatility and downside risk relative to the competing fund groups from (Table 1).

Hedge funds using artificial intelligence consistently have the lowest drawdowns and best risk-adjusted returns (Sharpe ratios), not just during the Covid-19 pandemic, but more generally in crisis situations and during major market risk events as shown in Table 3.

Table 3: AI / Machine Learning Hedge Fund Returns During Key Market Risk Events

\begin{tabular}{cccccc}
\hline Date & Event & $\begin{array}{c}\text { Al Hedge Fund } \\
\text { Index }\end{array}$ & $\begin{array}{c}\text { CTA / Managed } \\
\text { Futures }\end{array}$ & $\begin{array}{c}\text { Trend Following } \\
\text { Index }\end{array}$ & Hedge Fund Index \\
\hline Mar-21 & Covid19 Drawdown & $\mathbf{3 . 2 7} \%$ & $\mathbf{1 . 8 2 \%}$ & $\mathbf{4 . 1 0 \%}$ & $-2.23 \%$ \\
\hline Nov-16 & Trump Win & $-0.94 \%$ & $-0.18 \%$ & $0.38 \%$ & $0.31 \%$ \\
\hline Jun-16 & Brexit & $1.29 \%$ & $2.32 \%$ & $4.18 \%$ & $0.32 \%$ \\
\hline Feb-16 & Oil Price Dip/China growth concerns & $-0.86 \%$ & $1.71 \%$ & $1.92 \%$ & $0.00 \%$ \\
\hline Jan-16 & Oil Price Dip/China growth concerns & $4.33 \%$ & $1.33 \%$ & $2.42 \%$ & $-1.74 \%$ \\
\hline Aug-15 & China Equity Crash & $0.72 \%$ & $-1.72 \%$ & $-2.54 \%$ & $-1.92 \%$ \\
\hline Jul-15 & China Equity Crash & $0.43 \%$ & $0.97 \%$ & $-2.25 \%$ & $-0.06 \%$ \\
\hline Jun-15 & Greek referendum & $1.84 \%$ & $-2.00 \%$ & $-3.28 \%$ & $-1.14 \%$ \\
\hline Jan-15 & Swiss Franc De-pegging & $1.30 \%$ & $3.23 \%$ & $3.87 \%$ & $0.78 \%$ \\
\hline Sep-14 & Oil Price Dip & $-0.57 \%$ & $198.00 \%$ & $333.00 \%$ & $-0.22 \%$ \\
\hline Jun-13 & Taper Tantrum & $1.56 \%$ & $-0.93 \%$ & $-1.68 \%$ & $-1.31 \%$ \\
\hline May-13 & Taper Tantrum & $1.55 \%$ & $-1.07 \%$ & $0.45 \%$ \\
\hline \multicolumn{5}{c}{} \\
\hline Source: Adapted from & Eurakahedge, 2017) to include Covid-19 Risk Assessment. & & \\
\hline
\end{tabular}


This answers the first part of our headline question: "Did algorithmic trading generate superior returns relative to discretionary trading during the Covid-19 pandemic?" - Clearly funds using artificial intelligence outperformed discretionary funds during the pandemic as shown in Table 2 with gains of $+3.37 \%$ and losses of $-2.23 \%$ respectively.

\subsection{Algorithmic Trading Performance after Covid-19 Drawdown (Post-April 2020)}

Hedge fund performance after Covid-19 drawdown highlights how funds performed in more normal and less extreme market environments. This highlights the fund manager's ability to profit in normal market conditions and more specifically in this period to benefit from and exploit post-Covid-19 opportunities.

Reviewing the results presented in Table 2 from a post-Covid-19 perspective we see that algorithmic trading using artificial intelligence earned returns of $+11.24 \%$ beating quant funds with returns of $+7.85 \%$ and $+10.92 \%$ and almost matching traditional discretionary funds with $+12.26 \%$. On a risk-adjusted basis AI funds outperform all funds and have the highest Sharpe ratios ${ }^{6}$.

Equivalently, from a CAPM perspective, when plotting the risk-return profile for each hedge fund group we see AI funds generate the highest returns per unit risk (Figure 9). The gradient of the lines in red through the fund returns and risk-free rate indicate the Sharpe ratio, which for AI funds is the closest to the Capital Market Line (CML) indicating AI funds are the most efficient on a risk-adjusted basis (Berk and DeMarzo, 2016; and Burgess, 2021).

For each of the funds from Table 1, we plot the annualized return and standard deviation. The slope of the red-lines denotes the Sharpe ratio, quoted in blue. We implied the risk-free rate as $2.0 \%$ using (Equation 1). The black and blue lines are for illustrative purposes and represent the CAPM CML and Efficient Frontier respectively.

In August 2020 (Institutional Investor, 2020) also reported that AI Tech Funds had vastly outperformed other funds, having produced cumulative returns of $34 \%$ in the three years through to May 2020, compared with a $12 \%$ gain for the global hedge fund industry over the same period. Furthermore, Bloomberg confirm that not only did AI funds outperform in the post-Covid-19 environment, they have also outperformed on a long-term basis as shown in Figure 10.

Comparing the hedge fund benchmarks from Table 1 we see that artificial intelligence hedge funds vastly outperform competitor funds.

Having confirmed that algorithmic trading has the potential to generate superior returns relative to discretionary trading we proceed to examine if they could provide a sustainable competitive advantage.

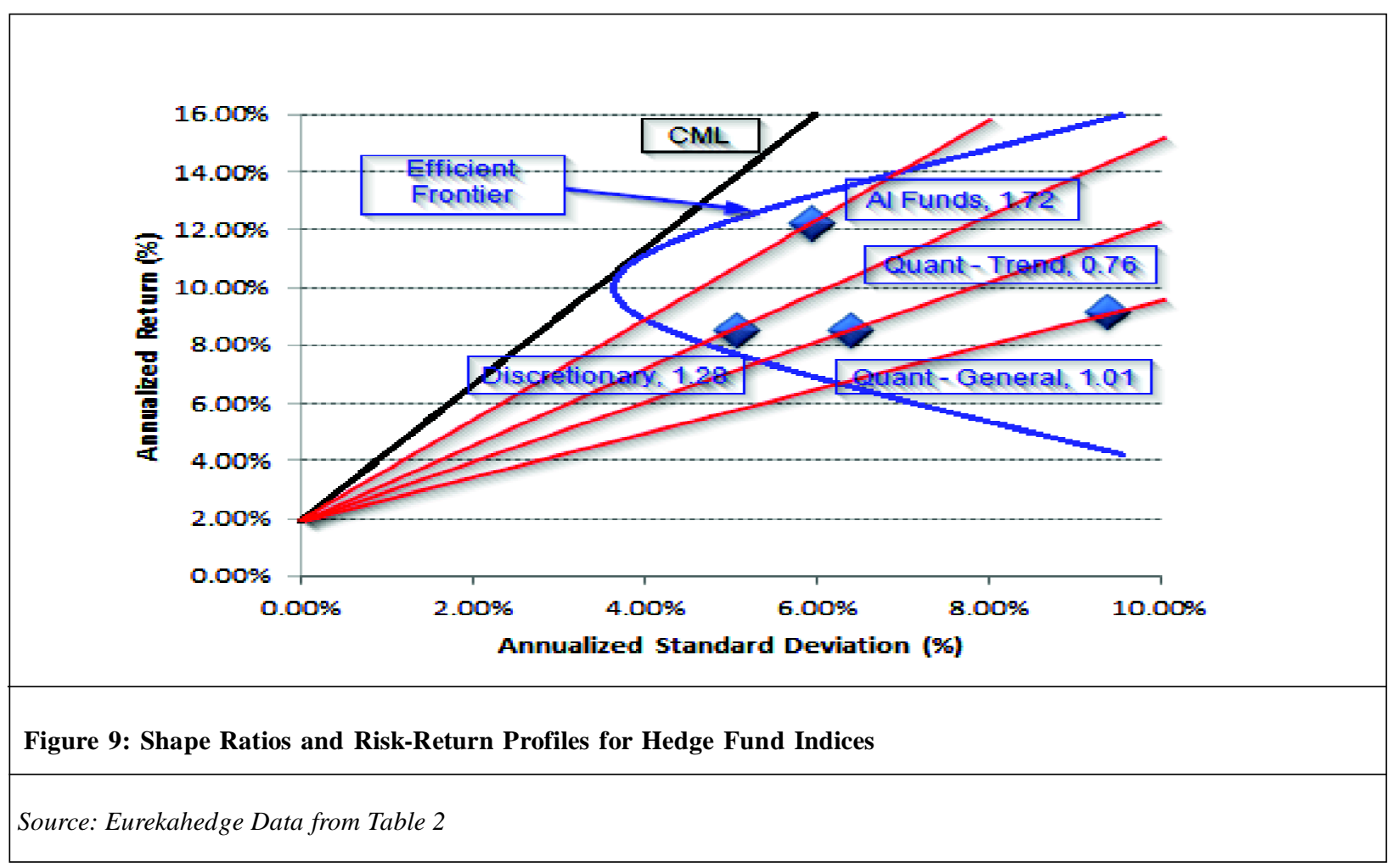

6 AI funds also have the highest Sortino ratios, where risk is measured as downside volatility. 


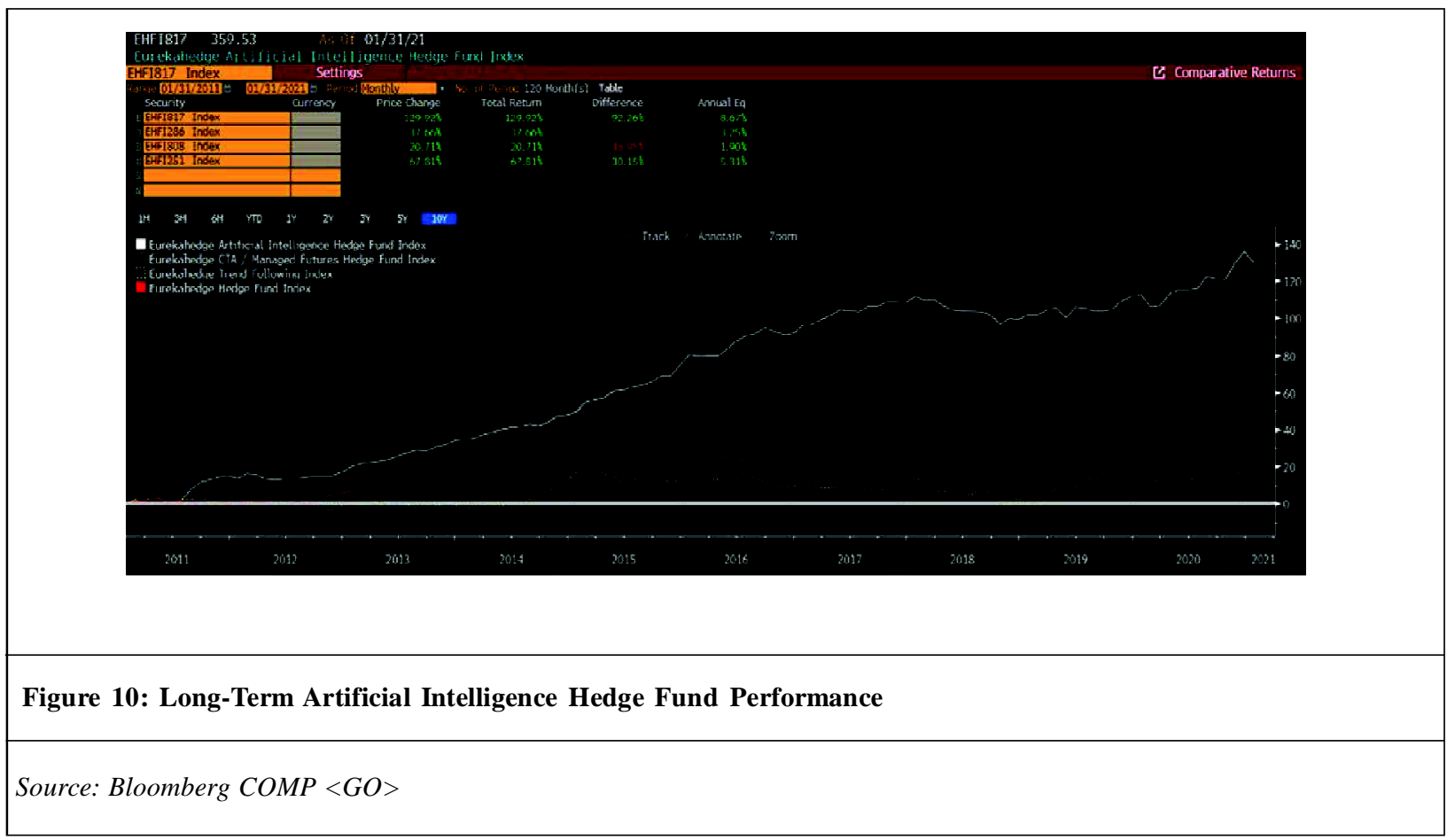

\section{Competitive Advantage}

As outlined in Burgess (2020c) the long-term survival of any organization relies upon its ability to well-manage resources to create dynamic capabilities valued by customers. Threshold capabilities are required to survive in a given market and achieve competitive parity. However dynamic capabilities utilize the entire value chain (Zenger, 2013). They are sets of resources, capabilities, skills and abilities (Figure 11), which together combine to form core competencies that can respond dynamically to environmental opportunities and threats. They have the potential to create a sustainable competitive advantage.

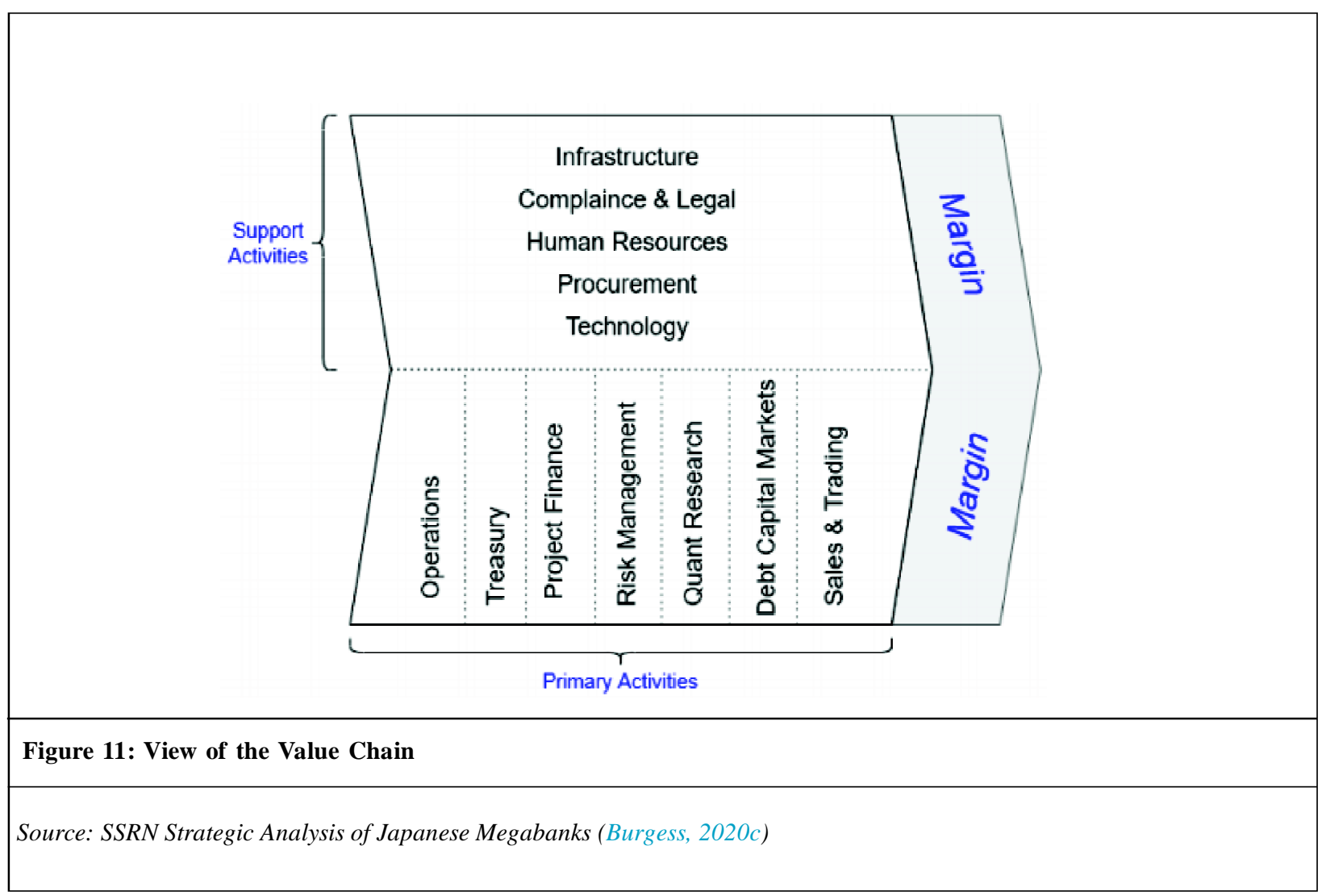




\begin{tabular}{|c|c|c|c|c|c|c|c|}
\hline & \multicolumn{2}{|c|}{ Opportunities (O) } & \multicolumn{5}{|c|}{ Threats (T) } \\
\hline & 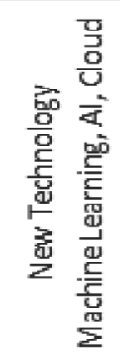 & 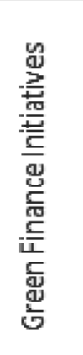 & 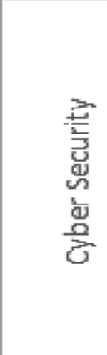 & 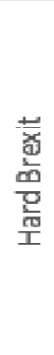 & 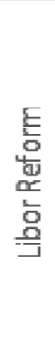 & 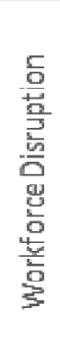 & 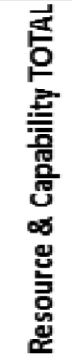 \\
\hline \multicolumn{8}{|l|}{ Strengths (s) } \\
\hline HR Excellence & & & & & & 5 & 5 \\
\hline Skilled Workforce & 5 & 5 & 2 & 2 & 5 & 5 & 24 \\
\hline Parent Co. Large Capital Base & 5 & 5 & 2 & 2 & 5 & 2 & 21 \\
\hline Agıle Pricing/Risk Analytics: & 5 & 5 & & & 10 & & 20 \\
\hline \multicolumn{8}{|l|}{ Weaknesses: (W) } \\
\hline Legacy Products & -3 & -3 & & & -5 & & -11 \\
\hline Poor Systems Infrastructure & -5 & -3 & -5 & & -5 & & -18 \\
\hline Capital Constraints & -3 & -5 & & & -5 & & -13 \\
\hline Limited Data Availability & -5 & -2 & & & & & -7 \\
\hline Limited Management Metrics & -3 & -3 & -3 & -3 & -3 & -3 & -18 \\
\hline RUS Total & -4 & -1 & -4 & $\mathbf{1}$ & 2 & 9 & 3 \\
\hline
\end{tabular}

\section{Figure 12: SWOT Analysis for RUS}

Source: Strategic Analysis of Japanese Megabanks (Burgess, 2020c)

Prior to assessing if algorithmic trading skills and capabilities could complement the existing value chain we performed a SWOT ${ }^{7}$ analysis (Whittington et al., 2020), see (Figure 12). This was to assess RUS's current capabilities, internal strengths and weaknesses, and current ability to manage the external opportunities and threats presented in Figure 1.

RUS are currently unable to monetize core competencies due to capital constraints, low trading volumes and high cost to revenue ratios. Furthermore limited performance metrics act as a business tax that disables management from understanding RUS's value proposition, its core strengths and weaknesses. It also diminishes their ability to maximize profits, reduce costs and manage key risks.

Furthermore using a competitor SWOT analysis (Figure 13) to contrast RUS's core competencies against key competitors reveals that RUS are only able to achieve competitive parity. RUS are better placed to manage external threats but poorly placed to exploit external opportunities. The SWOT analysis suggests RUS are more risk averse than its competitors. It is well placed to manage external threats from coronavirus workforce disruption to regulatory Libor reforms (Burgess, 2019a). However it is poorly placed to exploit advances in technology and lucrative government green finance initiatives.

A VRINO $^{8}$ analysis (Galpin, 2020) helps to evaluate if, how and to what extent an organization has a value chain (Figure 11) with resources and capabilities that when combined can achieve and sustain a competitive advantage (Whittington et al., 2020).

We performed a VRINO analysis, in Burgess (2020c), based on RUS's current capabilities and value chain. In this paper we extend this analysis to examine if investing in algorithmic trading capabilities ${ }^{9}$ and combining this with the existing "agile pricing and risk analytics" (Burgess, 2020c) could create a new core competency "Advanced Automation of Pricing, Risk and Execution" that could offer superior trading and risk management capabilities and give RUS a sustainable competitive advantage. The VRINO analysis is performed below.

An acronym for strengths, weaknesses, opportunities and threats

8 VRINO is an acronym for Valuable, Rate, Inimitable, Non-substitutable and Organisationally Appropriable, sometimes also referred to as VRIO without the Non-substitutable element.

9 In this paper we are specifically referring to algorithmic trading systems that use artificial intelligence, machine learning and predictive technologies. 


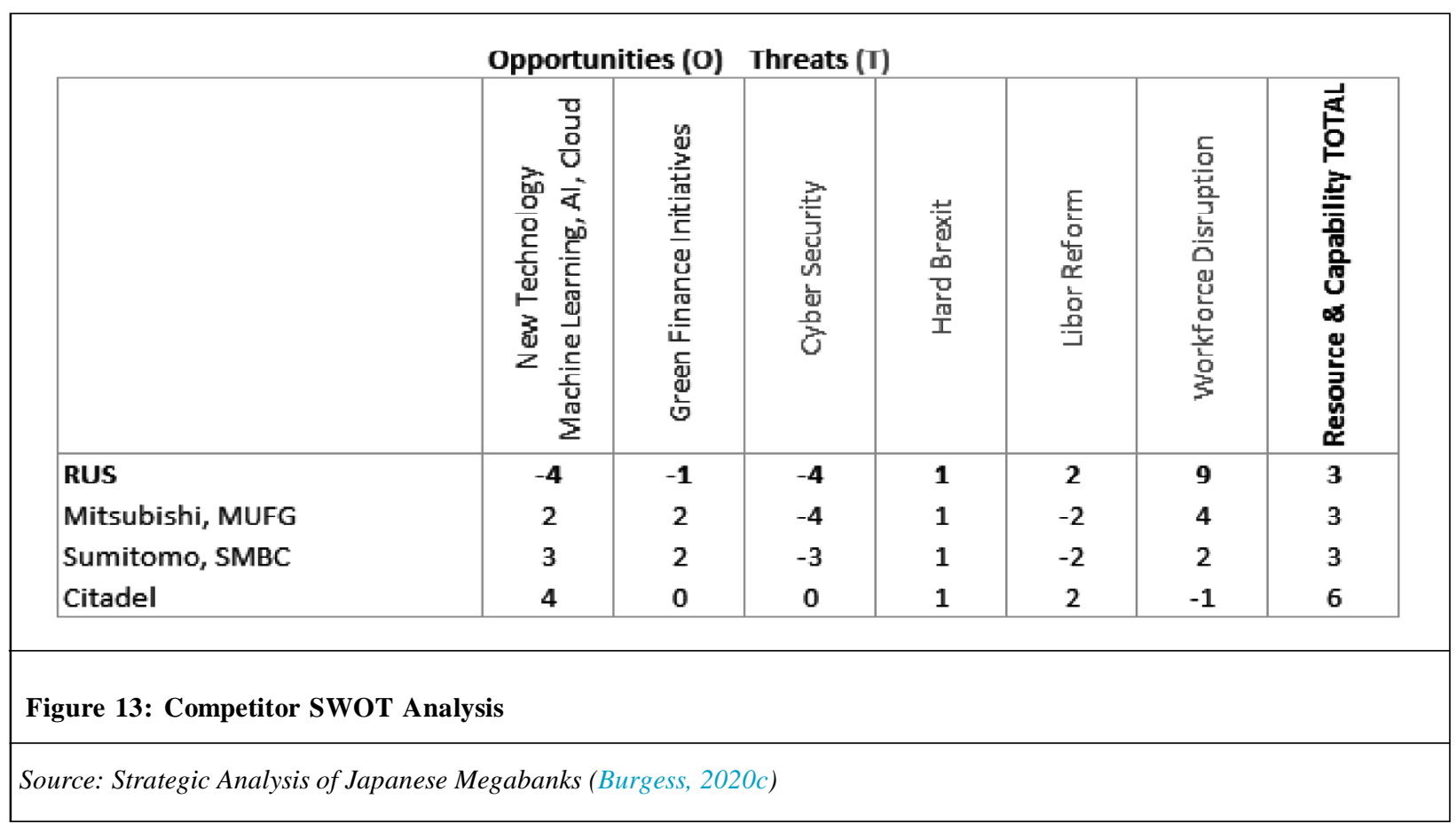

\subsection{VRINO Analysis - Valuable}

The new core competency would facilitate sophisticated state-of-art trade execution and orders could be worked systematically to reduce market frictions to achieve the best price. This is valuable to customers as it would facilitate better transaction prices and reduce human error.

It is valuable to RUS as it would also reduce human resource costs, which are the biggest costs of the organization incur. It would also reduce operational costs, create economies of scale, improve cross-selling opportunities and would enable RUS to outperform competitors, charge clients lower fees, compete more aggressively on price to win market share and provide elevated levels of client service.

There is a strong possibility algorithmic trading plays a key role in generating superior returns. As demonstrated by hedge fund managers using artificial intelligence, who have better managed market drawdowns and outperformed other funds on a risk-adjusted basis as indicated by their higher Sharpe ratios (Figure 9).

\subsection{VRINO Analysis - Rare}

We performed a strategy canvas analysis to produce a value curve for RUS and its competitors (Figure 14). A value curve measures perceived performance against Critical Success Factors (CSFs). It can be a subjective process and difficult for managers to agree on which critical success factors to prioritize as highlighted by Kim and Mauborgne (2002). The analysis highlighted that algorithmic trading capabilities, digital services and technology innovation are rare skills that could exploit competitor weakness. Algorithmic trading presents a lucrative, monopolistic, 'Blue Ocean' investment opportunity, where profit margins are wider as markets are less competitive and less congested.

\subsection{VRINO Analysis - Inimitable}

It is extremely difficult to imitate the new core competency, because it is nuanced, complex and requires tacit knowledge of the intricate connectivity between value chain components. Furthermore it is unique to the bank making it nontransferrable and inimitable.

\subsection{VRINO Analysis - Non-Substitutable}

It would be expensive and complex to replace or substitute the new core competency. As it would be costly to set-up a substitute and require niche technical expertise. Furthermore it would be difficult to substitute and replace automated algorithmic processes with a manual process. As a human managed process would be unable to process the vast amounts of data required or compete with the economies of scale and the speed of performance of an automated process. 


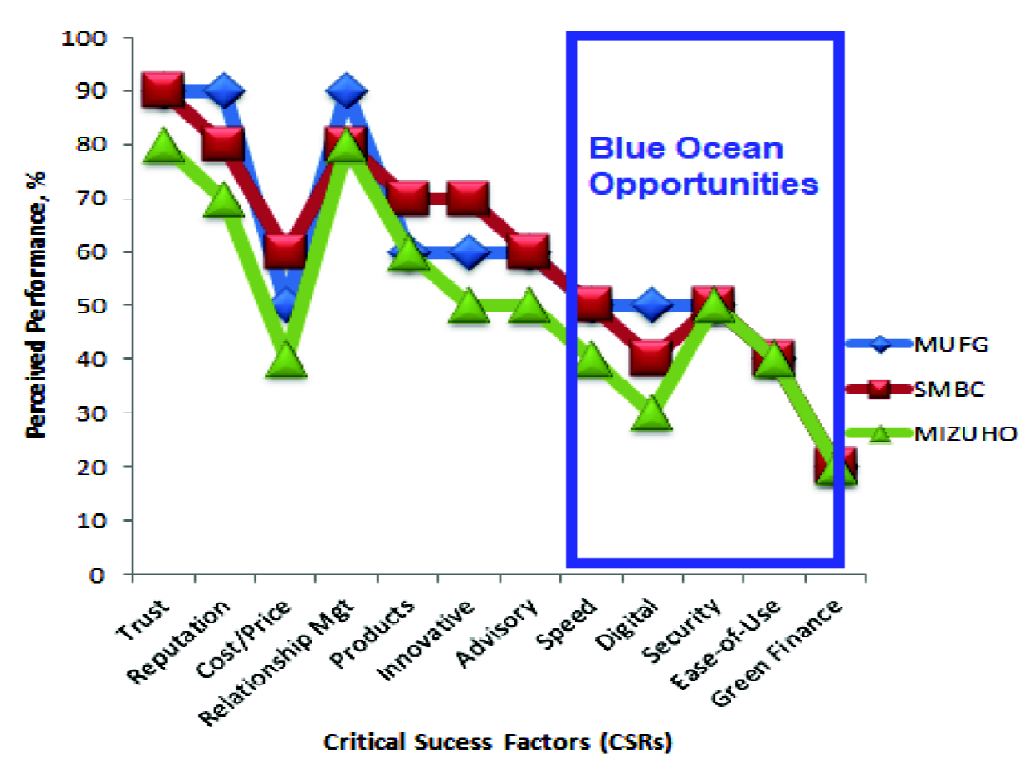

Figure 14: Strategy Canvas - Competitor Value Curve Analysis

Source: Strategy Canvas Analysis \& Competitor Benchmarking (Burgess, 2020e)

\subsection{VRINO Analysis - Organizationally Appropriable}

The new core competency is highly organizationally appropriable and could help to monetize existing capabilities and facilitate many new revenue generating opportunities. Likely benefits include:

Enhanced Returns

- Increased investment returns and sharpe ratios, see (Table 2 and Figure 9).

- $\quad$ Advanced market forecasting, prediction and trading signal capabilities.

- Increased transaction speeds and ability to exploit arbitrage opportunities.

- Automated execution, hedging and advanced order book management.

Advanced Risk Management

- $\quad$ Advanced risk and drawdown management, see (Tables 2 and 3).

- Reduction in human emotion/bias, human error and "fat finger" mistakes.

- Advanced order management - can simultaneously execute and hedge.

- More diversification opportunities and reduced idiosyncratic risk (Burgess, 2021).

Improved Client Services and Market Share

- Lower transaction costs and more competitive pricing.

- Ability to work large orders without moving the market.

- Hybrid or fully-automated 'robo research' and 'robo sales' services.

- Improved client services: Automation of repetitive tasks would free-up human resources for high value client service items.

- $\quad$ Advanced research leveraging broad market, social media and client data analysis.

- Improved market share and client coverage capacity.

- $\quad$ Enhanced cross selling opportunities.

Cost Savings

- Automation of repetitive tasks and human resource savings. 
- Lower operational costs

- Scalable services and economies of scale

Even if RUS could only monetize a fraction of these opportunities the new core competency has the potential to increase revenues significantly, reduce risk and lower costs. Furthermore RUS could opportunistically go after the quick and easy revenue enhancing targets first and use the profits for sustained reinvestment and innovation.

The VRINO analysis indicates that investing in algorithmic trading would give a sustainable competitive advantage as summarized in Figure 15.

\begin{tabular}{|c|c|c|c|c|c|c|}
\hline & & V & $\mathrm{R}$ & I & $\mathrm{N}$ & $\mathrm{O}$ \\
\hline & Strengths & $\frac{\frac{d}{D}}{\frac{0}{J}}$ & 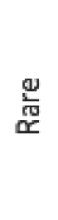 & 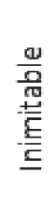 & 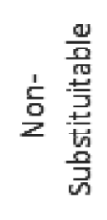 & 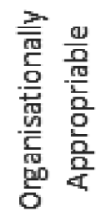 \\
\hline 1 & HR Excellence & $\checkmark$ & $x$ & $x$ & $x$ & $x$ \\
\hline 2 & Skilled Workforce & $\checkmark$ & $x$ & $x$ & $x$ & $\mathbf{x}$ \\
\hline 3 & Parent Co. Large Capital Base & $\checkmark$ & $\checkmark$ & $x$ & $x$ & $\mathbf{x}$ \\
\hline 4 & Agile Pricing \& Risk Analytics ${ }^{1}$ & $\checkmark$ & $\checkmark$ & $\checkmark$ & $\checkmark$ & $\mathbf{x}$ \\
\hline 5 & Advanced Automation of Pricing, Risk \& Excecution ${ }^{2}$ & $\checkmark$ & $\checkmark$ & $\checkmark$ & $\checkmark$ & $\checkmark$ \\
\hline \multicolumn{7}{|c|}{${ }^{1}$ Facilitates Sophisticated, Fast, Bespoke Trading \& Risk Capabilities } \\
\hline \multicolumn{7}{|c|}{${ }^{2}$ Automated, Adaptive \& Predictive Pricing, Risk \& Execution using Machine Learning } \\
\hline \multicolumn{7}{|c|}{ Figure 15: VRINO Analysis } \\
\hline \multicolumn{7}{|c|}{ Source: Adapted from Strategic Analysis of Japanese Megabanks (Burgess, 2020c) } \\
\hline
\end{tabular}

This answers the second part of our headline question: "Do they provide a sustainable competitive advantage?" - Yes they certainly provide a sustainable competitive advantage. Specifically for RUS, they would enable existing resources and capabilities to be organizationally appropriable, monetizable and enable RUS to improve its strategic position from competitive parity to that of having a competitive advantage by shoring up technological weaknesses to exploit market opportunities.

\section{What Should My Organization Do?}

Having established that algorithmic trading technologies have high revenue generating potential and could provide a sustainable competitive advantage for RUS (Figure 15); how should RUS acquire this skill and integrate it with existing resources and capabilities?

The goal of a Merger \& Acquisition (M\&A) is to acquire new resources and capabilities to build up a firm's existing capabilities, increase firm value and gain market share. Therefore we use M\&A tools and frameworks from (SBS4, 2020) and (Galpin, 2020), as they are perfectly designed to answer this question.

In order to acquire algorithmic trading capabilities, RUS need to consider if it should build or buy the resources and technologies required. We outline the pros and cons of each approach in Figure 16.

RUS could pursue organic growth via in-house expertise and internal alliances. Alternatively the core competency could be acquired via vendor software purchases, fintech partnerships, joint-ventures or even a fintech acquisition.

An organic approach is most suitable for RUS and most compatible with RUS's requirements and concerns:

Cost Cutting and Capital Constraints

- $\quad$ RUS is cost cutting, has capital constraints and looking for a cost effective solution.

- $\quad$ Need for niche technical expertise and careful cost management (Burgess, 2019a). 


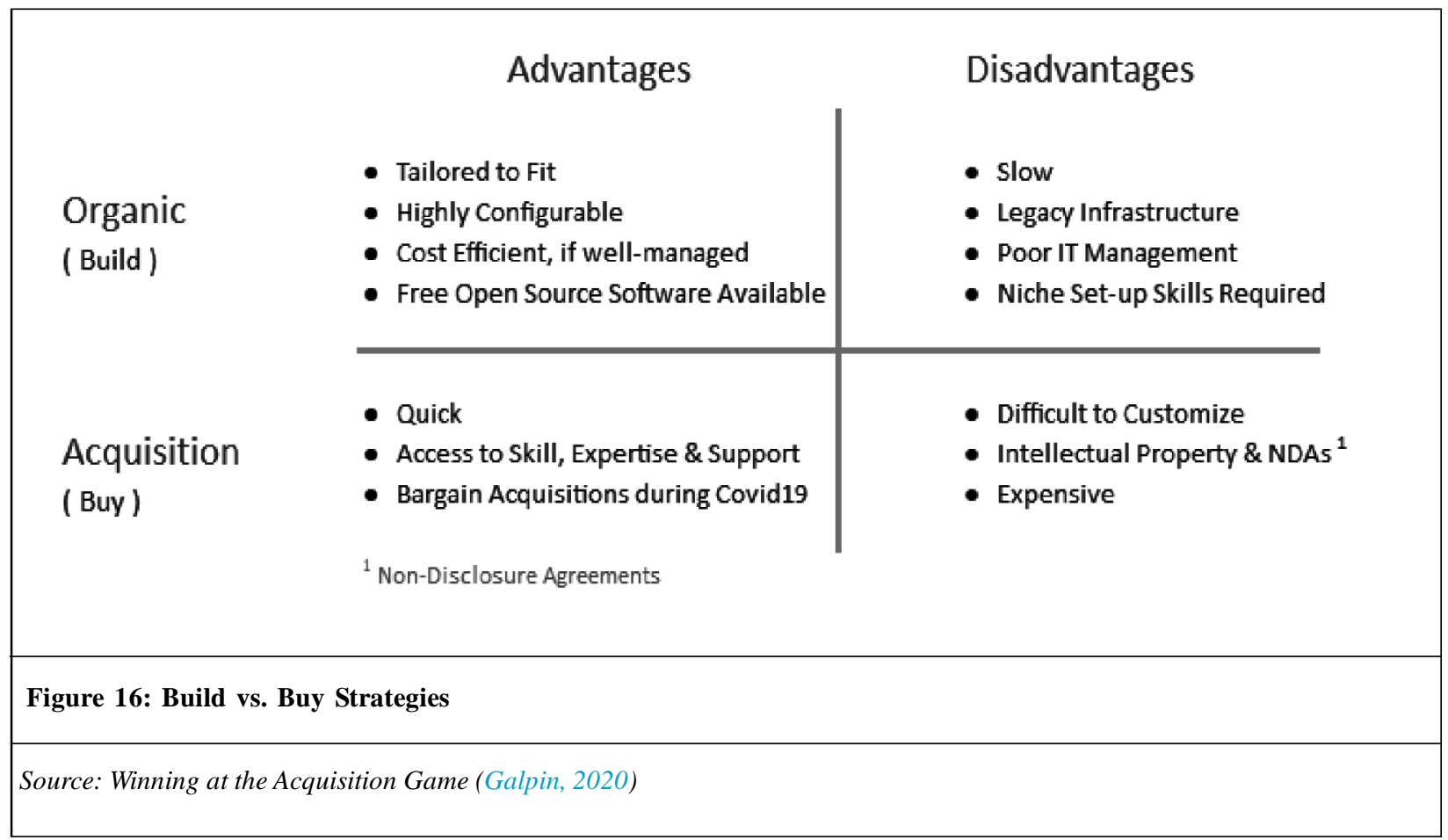

- $\quad$ Make use of free open source vendor solutions (Scikit-Learn, n.d.; and TensorFlow, n.d.)

Risk Aversion

- Want to take an experimental approach before committing capital.

- $\quad$ Increased revenue opportunities must be demonstrable and evidenced.

- Want an incremental program of work that focuses initially on low cost easy wins.

- Gradual change to minimize disruption.

- Workforce require time to train and adapt to new processes.

Data Protection

- $\quad$ RUS is concerned about proprietary data leakage and GDPR. ${ }^{10}$

- Vendors might share RUS alpha generation ideas to win new customers.

- A vendor Non-Disclosure Agreement (NDA) is not considered sufficient protection.

As illustrated in Figure 16 organic growth would allow RUS to take a cost-effective, risk-averse and incremental integration approach. Organic solutions are tailored to business needs, highly configurable and over time they better help establish in-house expertise. Downside challenges would likely arise from having to work with expensive legacy infrastructure, outdated IT policies and poor IT management. Manager skill is critical for success to navigate IT challenges and if managed well this approach could be a cost effective solution.

Following (Ansoff, 1957) we recommend the integration plan illustrated in Figure 17. We have high confidence in this approach as it was previously used successfully to establish the "agile pricing and risk analytics" core competency.

\subsection{Ansoff Integration Plan}

\subsubsection{Market Penetration}

First, consolidate core business lines and focus on market penetration and growing core rates trading and fixed income businesses, which are well-established yet have more potential.

\subsubsection{Product and Services Diversification}

Second, diversify by product and asset class to provide advanced services and support for credit derivatives, foreign exchange, interest rate swaptions, convertible bonds and equity businesses.

10 The General Data Protection Regulation (GDPR) is a legal framework in the European Union (EU) that sets strict guidelines for the collection and processing of personal information. 


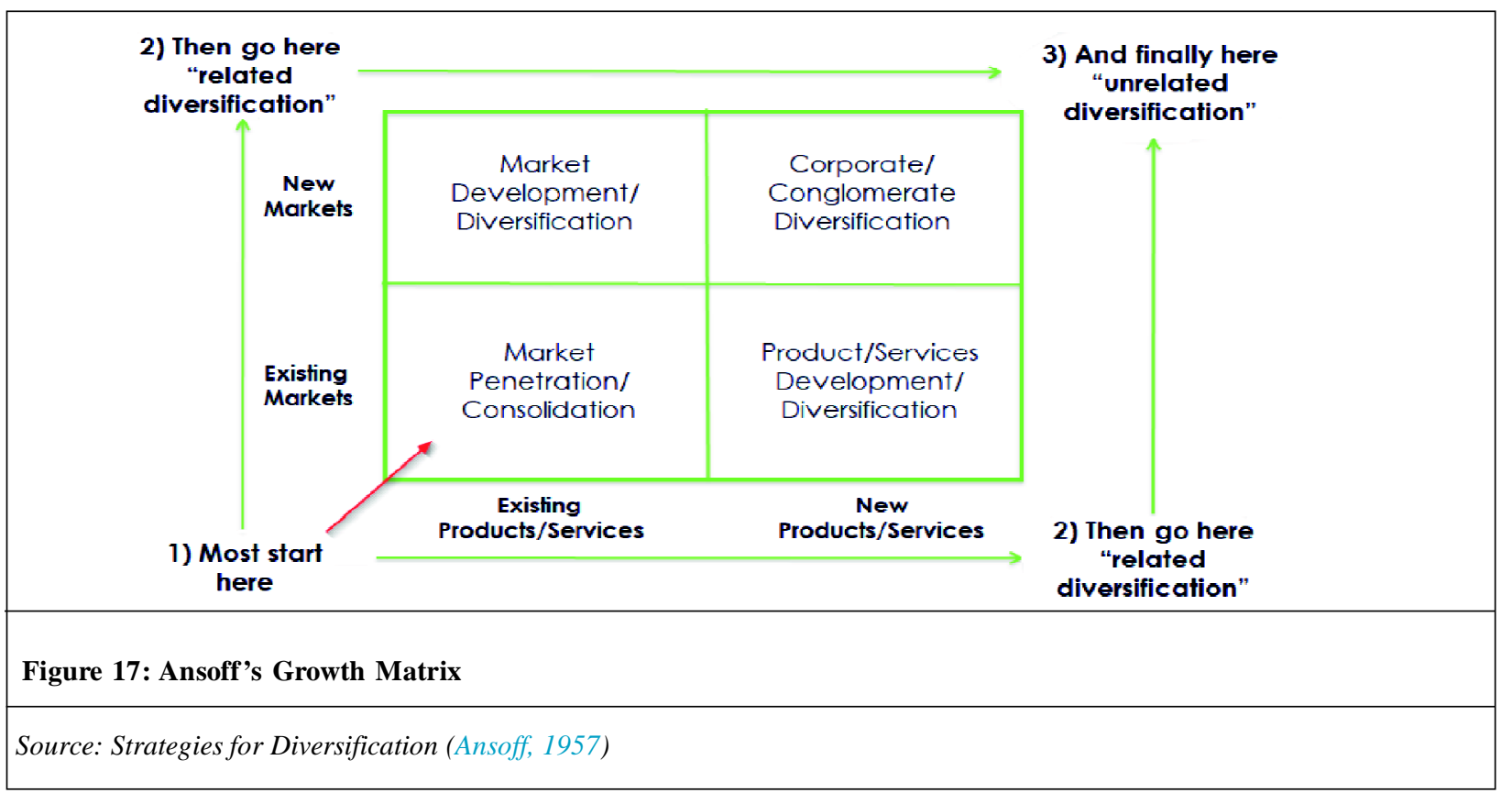

\subsubsection{Market Diversification}

Thirdly, diversify by market, starting with the most similar business entities, namely, RUS Bank London, RUS Securities New York, Hong Kong then Tokyo (in this order). A cautious more arm's length approach should be taken with overseas branches, where cultural CAGE ${ }^{11}$ distances (Ghemawat and Altman, 2019) can lead to lengthy P\&L ${ }^{12}$, cost, ownership and other internal disputes that often destroy rather than create value.

When integrating algo capabilities, RUS should focus on enhancing core business performance and limited related diversification. Research shows (Whittington et al., 2020) that it is important to diversify, but not over-diversify, as unrelated diversification is ineffective and often lowers performance, as illustrated in Figure 18.

\begin{tabular}{|c|c|}
\hline Performance & Ligh \\
\hline Figure 18: Diversification and Performance & $\begin{array}{c}\text { Related } \\
\text { Limited } \\
\text { Diversification }\end{array}$ \\
\hline Source: Exploring Strategy (Whittington et al., 2020) & $\begin{array}{c}\text { Unrelated } \\
\text { Diversified }\end{array}$ \\
\hline
\end{tabular}

It will be important to establish internal alliances between quant and research teams to steer the innovation, train the trading and sales teams and assist with data analyses to be used for identifying cross selling opportunities and trading signals for alpha generation.

11 CAGE distances track cultural, administrative, geographical and economic differences.

$12 \mathrm{P} \& \mathrm{~L}$ is an acronym for profit and loss. 
For RUS a cost-effective way to transition towards using machine learning techniques would be to consider using free open source Scikit-learn and TenorFlow ${ }^{13}$ analytics to complement the existing in-house analytics with PCA ${ }^{14}$ and other highly sought after machine learning techniques, tools and frameworks for pricing and risk management.

Initially machine learning processes should be kept simple to use. To enhance revenue opportunities machine learning must be implemented into processes in a way that is complementary and organic to existing workflows in order to combine the best human financial expertise with the best AI/ML techniques. This is often referred to as a Quantamental ${ }^{15}$ approach (Luipez de Prado, 2018), where we combine quantitative approaches using high-end computers, mathematical models and big data with fundamental methods where humans manually analyze investment opportunities to generate better risk-adjusted returns (Lynch, 2018; and Smigel, n.d.). Moreover, as automation frees human resource, human effort should be reassigned to high value-add work items.

RUS should incrementally enhance existing trading and sales capabilities to target earnings growth ${ }^{16}$, starting by enhancing data analysis and the automation of well-understood tasks and processes such as below:

Targeted Algo enhancements for earnings growth

- Enhance trader analytics for better pricing, risk and trading signals.

- Automate research and trading ideas.

- Enhance client data gathering \& $\mathrm{RFQ}^{17}$ analysis.

- Enhance sales processes to identify cross-selling opportunities.

- Auto hedging (humans execute main deal, but with auto-hedging).

- Auto execution (with human oversight only).

- Advanced execution services to work larger orders efficiently.

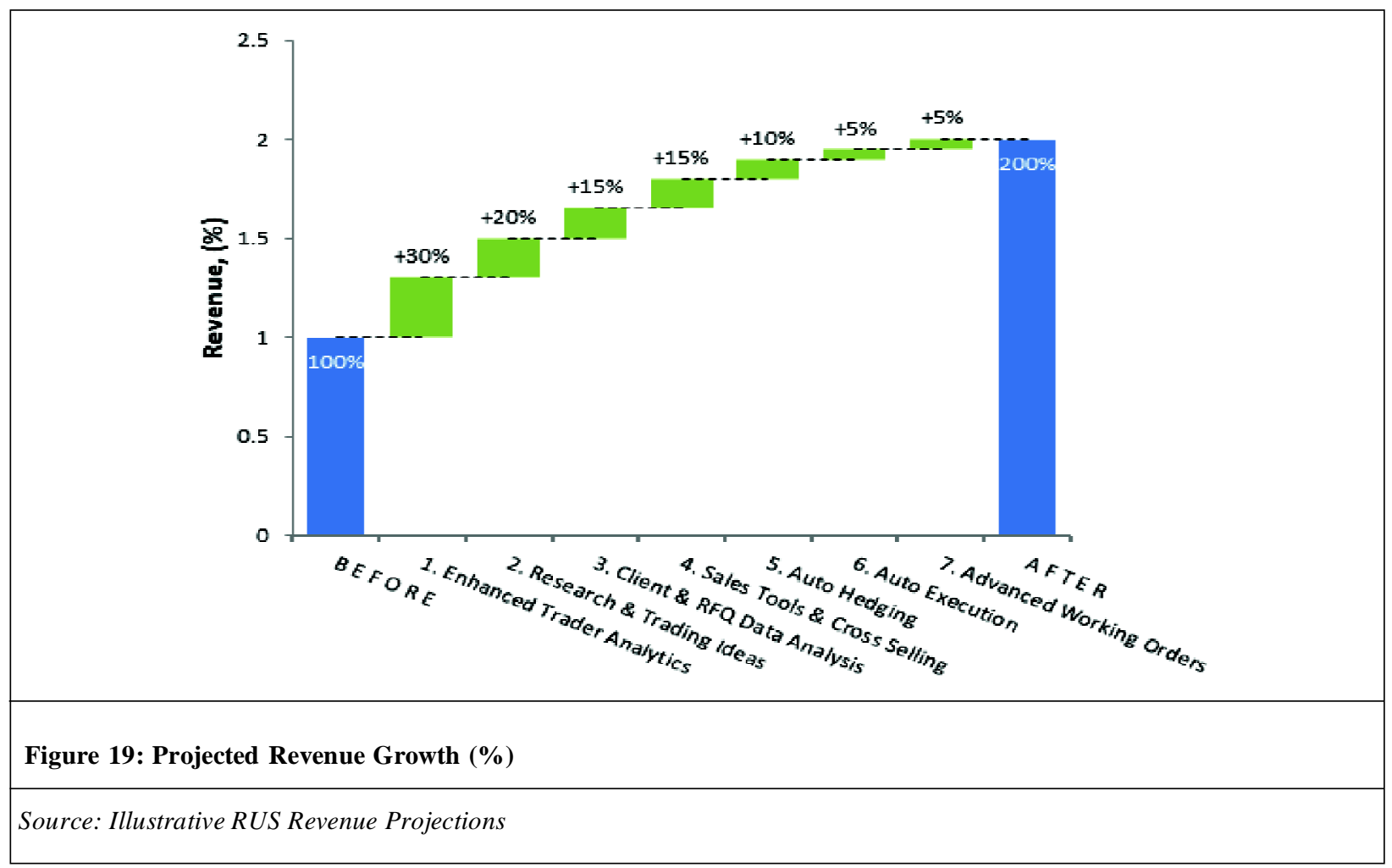

13 Scikit-learn and TensorFlow are an open source analytics libraries that provide machine learning tools for data analysis, see (Scikit-Learn, n.d.) and (TensorFlow, n.d.) respectively.

14 RUS is keen to explore the use of Principal Component Analysis (PCA), which is a technique for reducing the dimensionality of a dataset to increase data interpretability whilst minimizing information loss.

15 This is a portmanteau combining "quant"itative and fund"amental" investing.

16 Increased earnings from both revenue growth and cost reduction.

17 An electronic price request is called a Request for Quote (RFQ). 
Even if only a fraction of the benefits from (Section 5.5) and (Figure 19) are monetized, algorithmic trading would have a significant positive impact on earnings. This would facilitate reinvestment to develop the new core competency to maturity, establish further economies of scale and facilitate sustainable growth.

\section{Conclusion}

We have learned that algorithmic trading strategies generated superior returns relative to discretionary trading during the Covid-19 pandemic and that they facilitate better management of major market drawdowns. We also showed that both during normal market conditions and times of crisis they generate superior risk-adjusted returns and exhibit higher Sharpe ratios.

An algorithmic trading strategy would allow RUS to dynamically respond to market events, better identify market opportunities, reduce costs, reduce operational risk, improve client services, increase market share and establish economies of scale. It would complement RUS's existing value chain to create a new core competency "Advanced Automation of Pricing, Risk and Execution" services, which would give RUS a sustainable competitive advantage.

These are unprecedented times for the world and financial markets; the economic outlook is uncertain yet cautiously optimistic. Coronavirus vaccines, continued workforce disruption, weak economies and government financial stimuli with tax hikes to follow dominate news headlines. There will be a clear paradox to both cut costs and innovate. We believe these risks will be best managed through an organic algo growth strategy, which will allow RUS to be innovative and stable (McGrath, 2012), whilst establishing a sustainable competitive advantage.

\section{References}

Ansoff, I. (1957). Strategies for Diversification, Harvard Business Review, 35(5), 113-124.

Barclay, Hedge. (2018). BarclayHedge Survey: Majority of Hedge Fund Pros Use AI/Machine Learning in Investment Strategies. Available at: https://www.barclayhedge.com/insider/majority-of-hedge-fund-pros-use-ai-machinelearning-in-investment-strategies

Berk, J., and DeMarzo, P. (2016). Textbook: Corporate Finance. Global Edition. Published by Pearson, ISBN 978-1-292$16016-0$.

Bloomberg. (2020). Human-Run Hedge Funds Trounce Quants in Covid Year. Available at: https://www.bloomberg.com/ news/articles/2020-12-30/human-run-hedge-funds-trounce-quants-in-year-defined-by-pandemic

Brealey, R. et al. (2014). Textbook: Principles of Corporate Finance. Global Edition. Published by McGraw Hill Education, ISBN 978-0-077-15156-0.

Brogaard, J. et al. (2011). UK Government Review: The Future of Computer Trading in Financial Markets. Available at: https://assets.publishing.service.gov.uk/government/uploads/system/uploads/attachment_data/file/289021/111241-dr10-high-frequency-trading-information-and-profits.pdf

Burgess, N. (2019a). An Introduction to Algorithmic Trading: Opportunities \& Challenges within the Systematic Trading Industry. Available at SSRN: https://ssrn.com/abstract=3466213

Burgess, N. (2020a). Strategic Analysis of Japanese Megabanks - Analysis 1 of 5 Changes in Relative Prioritization of Stakeholders \& the Implication for Corporate Strategy. Available at SSRN: https://ssrn.com/abstract=3645549

Burgess, N. (2020b). Strategic Analysis of Japanese Megabanks - Analysis 2 of 5 Macro Scenario Analysis of Financial Services. Available at SSRN: https://ssrn.com/abstract=3645551

Burgess, N. (2020c). Strategic Analysis of Japanese Megabanks - Analysis 3 of 5 Core Competency Development for Competitive Advantage. Available at SSRN: https://ssrn.com/abstract=3645553

Burgess, N. (2020d). Strategic Analysis of Japanese Megabanks - Analysis 4 of 5 Financial Services Industry Analysis. Available at SSRN: https://ssrn.com/abstract=3660674

Burgess, N. (2020e). Strategic Analysis of Japanese Megabanks - Analysis 5 of 5 Strategy Canvas Analysis \& Competitor Benchmarking. Available at SSRN: https://ssrn.com/abstract=3660679

Burgess, N. (2021). How Risky is your Project Really? Corporate Finance Strategies for Assessing Risk. Available at SSRN: https://ssrn.com/abstract=3748822

Esposito, A. (2020). Morning Star, How Tech Funds Performed in the Covid-19 Crisis, 7 April 2020. Available at: https:/ /www.morningstar.co.uk/uk/news/201203/how-tech-funds-performed-in-the-covid-19-crisis.aspx 
Eurekahedge. (n.d.). Eurekahedge is an independent data provider and alternative research firm that specializes in hedge fund databases. Available at: https://www.eurekahedge.com/

Eurekahedge. (2017). Eurekahedge Research: Artificial Intelligence: The New Frontier for Hedge Funds, (1/2). Available at: https://www.eurekahedge.com/Research/News/1614/Artificial-Intelligence-AI-Hedge-Fund-Index-StrategyProfile

Eurekahedge. (2018). Eurekahedge Research: Artificial Intelligence: The New Frontier for Hedge Funds, (2/2). Available at: https://www.eurekahedge.com/Research/News/1724/Artificial-Intelligence-Hedge-Fund-Index-Strategy-Profile2-February-2018

Factor Research. (2020). Hedge Fund Battle: Discretionary vs. Systematic Investing. Available at: https:// www.factorresearch.com/research-hedge-fund-battle-discretionary-vs-systematic-investing

Friedman, B. (2019). Prequin Blog: The Rise of the Machines: AI Funds Are Outperforming the Hedge Fund Benchmark. Available at: https://www.preqin.com/insights/research/blogs/the-rise-of-the-machines-ai-funds-areoutperforming-the-hedge-fund-benchmark

Galpin, T. (2020). Textbook: Winning at the Acquisition Game-Tools, Templates and Best Practices Across the M\&A Process. Oxford University Press, ISBN 978-0-19-885856-0.

Ghemawat, P., and Altman, S. (2019). The State of Globalization in 2019, and What it Means for Strategists. Harvard Business Review. Available at: https://hbr.org/2019/02/the-state-of-globalization-in-2019-and-what-it-means-forstrategists

Institutional Investor. (2020). AI-Powered Hedge Funds Vastly Outperformed, Research Shows. Available at: https:// www.institutionalinvestor.com/article/b1 mssrswn 1 mpr0/AI-Powered-Hedge-Funds-Vastly-OutperformedResearch-Shows

JP Morgan. (2019). JP Morgan Asset Management Portfolio Insights, Machine Learning in Hedge Fund Investing Alternatives for Uncorrelated Income. Available at: https://am.jpmorgan.com/ca/en/asset-management/ institutional/insights/portfolio-insights/machine-learning-in-hedge-fund-investing/

Kim, W., and Mauborgne, R. (2002). Charting Your Company's Future. Harvard Business Review. Available at: https:// hbr.org/2002/06/charting-your-companys-future

Lüpez de Prado, M. (2018). Textbook: Advances in Financial Machine Learning, $1^{\text {st }}$ Edition, John Wiley \& Sons, ISBN: 978-1-1109-48208-6

Lynch, V. (2018). TechCrunch Publication: 3 ways to Avoid Bias in Machine Learning. Available at: https:/techcrunch.com/ 2018/11/06/3-ways-to-avoid-bias-in-machine-learning

McGrath, R. (2012). How the Growth Outliers Do It. Harvard Business Review. Available at: https://hbr.org/2012/01/howthe-growth-outliers-do-it

McKinsey. (n.d.). Impact on Economies - Data Graphics, Insights from Leaders, and Stories that Illustrate the Impact of COVID-19 on Economies. McKinsey \& Company: Available at: https://www.mckinsey.com/about-us/covidresponse-center/covid-19-impact/impact-on-economies\#Macroeconomic

McKinsey. (2021). The Coronavirus Effect on Global Economic Sentiment, Jan 2021. McKinsey \& Company Survey: Available at: https://www.mckinsey.com/business-functions/strategy-and-corporate-finance/our-insights/thecoronavirus-effect-on-global-economic-sentiment

Robinson, G. (2020). International Investment Case Study: Covid-19 Strengthens the Case for AI in Fund Management - study. Available at: https://www.internationalinvestment.net/news/4018595/covid-19-strengthens-case-ai-fundmanagement-study

SBS1. (2020). Course in "Financial Strategy" as part of Postgraduate Diploma in Financial Strategy taught by Richard Whittington, Säid Business School, University of Oxford.

SBS2. (2020). Course in "Business Finance" as part of Postgraduate Diploma in Financial Strategy taught by Ilaria Piatti, Säid Business School, University of Oxford.

SBS3. (2020). Course in "Corporate Valuation" as part of Postgraduate Diploma in Financial Strategy taught by Martin Schmalz, Säid Business School, University of Oxford.

SBS4. (2020). Course in "Financial Strategy for Growth" as part of Postgraduate Diploma in Financial Strategy taught by Timothy Galpin, Säid Business School, University of Oxford. 
Scikit-Learn. (n.d.). Scikit-learn User Guide: Simple and Efficient Tools for Data Analysis. Available at: https://scikitlearn.org/stable/user_guide.html

Skeel, D. (2020). Report: Bankruptcy and the Coronavirus. April 21, 2020. Available at: https://www.brookings.edu/ research/bankruptcy-and-the-coronavirus/

Smigel, L. (n.d.). Analyzing Alpha Blog: "Quantamental: What is it \& Why it works". Available at: https:// analyzingalpha.com/quantamental

Statista1. (n.d.). Value of Assets Managed by Hedge Funds Worldwide. Available at: https://www.statista.com/statistics/ 271771/assets-of-the-hedge-funds-worldwide/

Statista2. (n.d.). Assets Under Management of the Largest Hedge Fund Firms Worldwide in June 2020. Available at: https://www.statista.com/statistics/273133/assets-under-management-of-the-largest-hedge-fund-firms/

Steinki, O., and Mohammad, Z. (2015). Common Metrics for Performance Evaluation: Overview of Popular Performance Measurement Ratios. Available at: https://papers.ssrn.com/sol3/papers.cfm?abstract_id=2662054

TensorFlow. (n.d.). TensorFlow: An End-to-End Open Source Machine Learning Platform. Available at: https:// www.tensorflow.org/

Walmsley, T. et al. (2020). Economics of Disasters and Climate Change Journal: The Impacts of Coronavirus on the Economy of the United States. Available at: https://doi.org/10.1007/s41885-020-00080-1

Whittington, R. et al. (2020). Textbook: Exploring Strategy, 12 ${ }^{\text {th }}$ Edition, Pearson Publishing, ISBN 978-1-292-28251-0.

WHO. (2021). World Health Organization Coronavirus Disease (COVID-19) Dashboard. Available at: https:// covid19.who.int/

Wigglesworth, R. (2020). The Financial Times - How Big Tech Got Even Bigger in the Covid-19 era, Robin Wigglesworth in Oslo, May 1, 2020. Available at: https:/www.ft.com/content/d2e09235-b28e-438d-9b55-0e6bab7ac8ec

Wilmott, P. (2019), Textbook: Machine Learning - An Applied Mathematics Introduction, Panda Ohana Publishing 2019, ISBN 978-1-9160816-0-4.

Wyman, O. (2014). The Hidden Alpha in Equity Trading - Steps to Increasing Returns with the Advanced use of Information. March 2014. Marsh \& McLennan Companies Publication: Available at: https://www.oliverwyman.com/ content/dam/oliver-wyman/v2/publications/2014/mar/The_Hidden_Alpha_in_Equity_Trading.pdf

Zenger, T. (2013). Value Chains \& Systems, Value Creation Maps and Strategy Metrics to Know the Value of your Firm. What Is the Theory of Your Firm? Harvard Business Review. Available at: https://hbr.org/2013/06/what-is-thetheory-of-your-firm

\section{Appendix}

\section{Case Study}

Organization: $\quad$ Rainbow \& Unicorn Securities, London (RUS)

Industry: $\quad$ Financial Services

Sector: $\quad$ UK Corporate Lending \& Project Finance

RUS provide financial services, trading expertise and risk management solutions within the interest rate, fixed income and credit markets. It specializes amongst other things in corporate lending and project finance within the UK and also Europe, Middle-East and Africa (EMEA).

RUS is fully owned by Rainbow \& Unicorn Financial Group Tokyo (RUFG), which has a sizable balance sheet, predominantly due to large Japanese deposits. Japanese investors are extremely risk-averse with many business relationships based on trust, reputation and long-term track formed over decades!

RUFG is one of three 'Japanese Megabanks' that dominate the financial services industry in Japan with combined deposits exceeding USD10 tn (Piece-of-Japan, n.d.). RUFG itself has assets of USD20 bn and employs 50,000 staff with 500 offices worldwide. 
Appendix (Cont.)

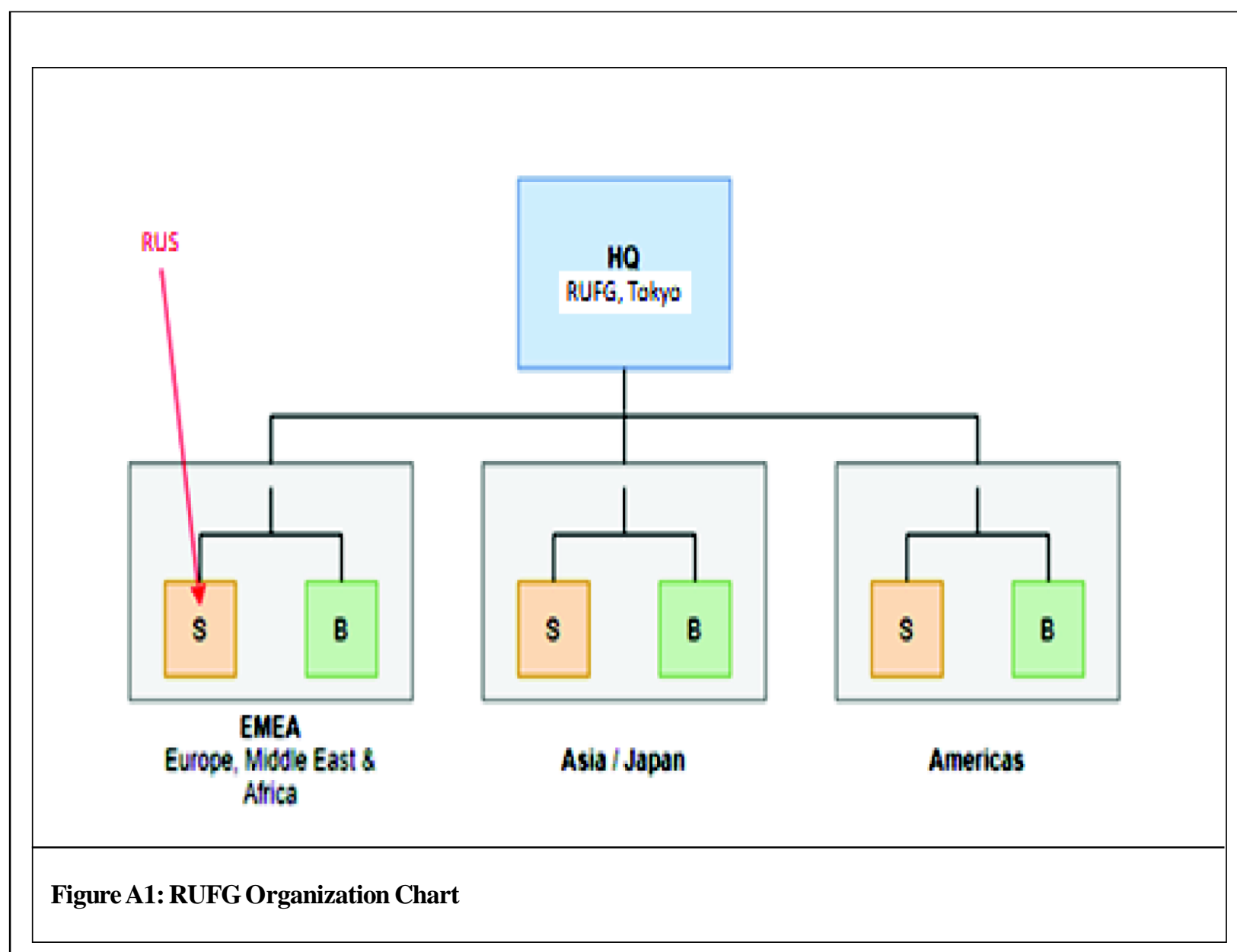

RUFG has 3 regional hubs to provide concentrated coverage in Europe \& EMEA, Asia \& Japan and the Americas. RUFG subsidiaries are separated with Corporate Banking (B) ring-fenced from the Investment \& Securities (S) business to satisfy legal and regulatory requirements.

Corporate Banking subsidiaries (B) have large balance sheets, good access to capital but poor legacy systems \& infrastructure. Investment \& Securities (S) businesses however have good technology and systems, but small balance sheets and little access to capital.

This case study is fictional, yet inspired by and adapted from real-world industry practice and first-hand experience. 